\title{
The Anthropometry of the Manual Work Space for the Seated Subject ${ }^{1}$
}

\author{
WILFRID TAYLOR DEMPSTER, W. CREIGHTON GABEL ${ }^{2}$ AND \\ WILLIAM J. L. FELTS ${ }^{3}$ \\ Department of Anatomy, University of Michigan, Ann Arbor
}

This paper is an exploration of the space-geometry of hand motions as they relate to young men in the seated posture. It is primarily a presentation in functional anthropometry, but the information derived should have practical use in improving the design of work areas. The pilot of an airplane, the driver of an automobile, the assembly worker or the machine operator all perform critical tasks with their hands. Controls and switches or objects upon which work is to be done must not merely be within reach, they should also be placed in the best possible spatial position relative to the operator. This ideal position has not yet been prescribed.

A detailed job analysis of a specific manual operation should of course improve the work area materially, but this information has little transfer value to another situation. Our work is concerned with the general range of hand motion, and we have attempted to find principles applicable to all work situations involving the seated position.

The approach is anthropometric-but in an entirely different sense from traditional anthropometry. Our measurements of the space within reach of the seated subject for all possible upper limb postures represent an approach to a dynamic anthropometry. The method of measurement is indirect, and it involves a certain novelty in anthropometric procedure; this shows up especially in the methods of gathering raw data, of making measurements, and of treating data.

A study of the functional-anatomical background for limb motion paralleled this study. Relevant work (Dempster, '55a, '55b, '56) involved a study of the motions of the major limb joints and a clarification of the characteristics of the link mechan- isms involved. (A link is the straight line or core line through a body segment between adjacent joint hinge points; it is the mechanical unit of body motion.) Older sources that cannot be ignored in a functional-anatomical-anthropometric study of this type are: Fischer ('07), Fick ('11), Strasser ('17), Braus ('21), Lanz and Wachsmuth ('35), and Mollier ('38). The Albert-Strasser globographic technique (Albert, 1876; Dempster, '56) for demonstrating the range of individual joint movement has provided useful background material. Equivalent work on living subjects is not available. Joint range studies on living subjects are typified by papers by Gilliland ('21), Sinelnikoff and Grigorowitsch ('31), Glanville and Kreezer ('37), Dempster ('55a) and Barter, Emanuel and Truett ('57). These studies are rather incomplete for certain joints and are not wholly satisfactory. Further work relating to age, sex, race, and occupation is warranted.

During the past decade or so, various authors have touched on aspects of the work place. Motion and time study workers (Barnes, '49; Branson, '52), psychologists (Chapanis, Garner and Morgan, '49; Hick and Bates, '50; McFarland, '53), engineers (Wallichs and Hulverscheidt, '35; Davis, '49; MacNeil, '54), and physiologists (Taylor and Blaschke, '51) have directed attention to spatial aspects of hand action. Dynamometric studies on hand forces by Hugh-Jones ('45) and by Darcus

1 This work was conducted under contracts with the Wright Air Development Center (Anthropometry Section), Wright-Patterson Air Force Base, Ohio.

2 Present Address: Department of Anthropology, Northwestern University, Evanston, Ill.

${ }^{3}$ Present Address: Department of Anatomy, University of Minnesota, Minneapolis. 
('51), Salter and Darcus ('52), Darcus and Salter ('53), Gaughran and Dempster ('55), Whitney ('58), and Dempster ('58) are relevant also. Randall, Damon et al. ('46) and especially King, Morrow and Vollmer ('47), King ('48, '52), McFarland et al. ('53) and McFarland, Damon and Stout ('55, '58) have considered dimensional problems of the seated subject. Commonly these references relate to empirical studies designed to meet specific problems of military and industrial personnel.

\section{Orientation}

If a part of the body such as the feet or buttocks is placed motionless on a supporting surface, the relative range of motion of some more mobile part, as the hand, may be defined in terms of a space geometry related to the immovable region. In effect, the body can be regarded as if it were within a three-dimensional Cartesian coordinate system which has its origin at a point on the supporting surface; the potential motion of any moving point-for instance some point on the hand-may be located within a region or space envelope with boundaries that may be scaled off relative to the $\mathrm{x}, \mathrm{y}$, and $\mathrm{z}$ coordinates. In the present study, the subjects were always seated. The envelope has a specific size, shape, and relation to the seat, trunk and legs; like the atom or solar system, however, it is bounded by an intangible surface which in this instance represents the extreme range of motion of the reference point of the hand in different directions. The space itself is merely the region of potential position of the hand point. In order to visualize the space envelope and its modifications for different conditions, both the seat and the hand reference points must be clearly identified.

For the seated subject the most stable body region is that part touching the seat. In our procedures the subject's head lay in contact with a dental head rest, the back was against the wooden seat back, the buttocks were well back on the seat, and the thighs were directed forward; thus the trunk was relatively stable for all hand positions. We have selected the midsagittal point of the junction of the seat and back as a reference (" $R$ ") point. This, in effect, is the zero point on an $\mathrm{x}, \mathrm{y}, \mathrm{z}$ coordinate system, to which are related the variable distance and angulation of the hand point as it travels in its outermost range over the surface of the space envelope.

The hand is a complex anatomical structure; if a part of it is to be a reference point, a precise posture must be assumed. Our approach starts with the recognition that the hand in a position of rest reflects a balanced system of minimal forces. This is a sort of mean hand posture from which other postures, including those involving finger activities, are deviations. Of course, there is no one rest position; it varies with how the hand rests with relation to the forearm and with the degrees of wrist flexion or extension. When, however, the hand and forearm lie passively and supine on a horizontal support with the wrist straight, the rest position is fairly average. This rest posture is approximately the same as when the hand lightly grips a cylindrical rod of about $30 \mathrm{~mm}$ ( $\left.11 / 8^{\prime \prime}\right)$ diameter. In our work the gripping of a standard rod proved an easy way of getting the hand to assume a position comparable to the mean rest posture. Now, when the hand gripped such a rod and the hand and forearm hung inert and vertically, the grip angle for 40 men relative to the long axis of the forearm was found to be $102^{\circ} \pm 6^{\circ}$ (obtuse angle on the radial side). (The grip axis was also about $14^{\circ}$ more supine than a line between the radial and ulnar styloids in the semi-prone position [Dempster, '55a].) The grip angulation increased as rods of notably larger diameters were grasped, but it was little changed for objects down to the size of a pencil.

In this study the axis of the grip was regarded as the core line of a $30 \mathrm{~mm}$ rod held in the hand. The thumb, or radial end of the rod, was used as a pole of reference. A point on the axis of the rod at the level of the third finger was arbitrarily taken as the hand point or grip centerhereafter called "grip point."

It is the outermost range of this grip point which, according to our usage, constitutes the surface of the space envelope. At the surface of the space envelope as defined by the grip point, the fingers or any other part of the hand may momentar- 
ily lie exterior to the grip point and to this extent they will project outside of the space envelope; similarly, the subject's body, and parts of the arm in certain positions, lies outside. Since the position of rest of the hand is a generalized mean posture, the space envelope for the index finger tip of the pointing hand, or for the pinch position of the fingers, can be derived by adding appropriate dimensions to the front surface of the space envelope for the resting hand (and subtracting from the rear surface).

The hand mass of the seated subject may be moved in either of two ways; it can move by rotation or by translation. In rotational or angular movement, the hand may be turned or twisted so that the angle of the grip axis is changed relative to the Cartesian system (or the floor or walls of a room). In translational movements, however, the grip angle remains constant; the hand in translational movement may be moved in a straight or curved line in any direction, but there is no angular change in the grip axis relative to the room. The hand may move through three degrees of freedom for translational movement-up and down, right and left, forward and backward. It may also move through three additional degrees of rotational freedomrotation in the sagittal plane, rotation in a coronal plane, or rotation in a transverse plane; but it has only these 6 degrees of freedom for potential movements. In our approach, translational movements of the hand, it will be seen, will receive primary attention.

When the hand, as the end member of a chain of extremity links, is kept in a constant angular orientation relative to a fixed " $R$ " point, movements at the wrist, elbow and shoulder permit an extensive range of translational hand movement. The space envelope enclosing the total range of such translational movements has a distinctive shape, which results from the unique combination of both the range and freedom of joint rotation by all of the upper limb joints and the limitation imposed by the constant orientation of the hand. The relative dimensions of the limb segments in different people, of course, also have a determinant relation to the shape but this effect is small.
We employ the term kinetosphere, from kineto, movement, plus sphere, region of, as an aid in analyzing the work area The term applies to the total range of translational movement of the end member of a series of links relative to an " $R$ " point; moreover it applies only to the arbitrary situation in which the end member is continually maintained in a constant angular orientation relative to a system of reference coordinates. In this study the hand was always directed straight forward; other kinetospheres could be defined for study with the hand pointing up, to the left, or down.

One should appreciate the nominal character of the kinetosphere. It is not merely another word for the work area but a concept which defines the space-shape which encloses a specific class of hand motion, translational movement only, so that it can be analyzed. The dimensions of such an envelope may be measured, and its shape may be reconstructed. The boundary outlines of sections through the kinetospheres can be grouped and compared, and similar kinetospheres from different individuals can be combined and averaged. The variability from subject to subject can be treated statistically. But kinetospheres have no existence apart from a rigidly imposed set of conditions, which limit the hand to purely translatory types of motion. The value of the concept is both in its use as an analytical tool for exploring body motion and in its ability for defining the space requirements for types of hand motion. The designer of planned work areas should thus be aided practically.

Each arbitrary hand orientation has only one kinetosphere. When a group of kinetospheres representing a related series of hand orientations, i.e., different classes of grip rotation for the same direction of hand pointing (viz., forward), are added to one another, we call the cumulative pattern a strophosphere from strophe, a turning or twisting, plus sphere, region of. The related series of hand grip orientations may represent a series of discrete wrist tilts in the sagittal plane (relative to the room); the series may involve a prone to supine twist about an anteroposterior hand axis (again relative to the room), or a wrist movement may be con- 
cerned with side-to-side hand postures about a vertical axis. The term applies to the space envelope, which permits three degrees of translational freedom for the hand plus one degree of rotational freedom relative to fixed coordinates. (Other strophospheres, not studied, can be visualized-the hand and forearm pointing up, in, out, or down, in each instance including a systematic grouping of rotational motions.) When one or two additional degrees of rotational freedom are included, the complexity increases, since the sequence of adding involves 6 possibilities of combinations; thus the value of the analysis breaks down.

Through kinetospheres and strophospheres, however, one may dissect the work area in terms of the hand positions which are possible in different regions of the total space within reach.

A more extensive term ergosphere, from ergo, work, plus sphere, region of, or work area, may apply to the total range of possible hand positions relative to an " $R$ " point; we would apply the term ergosphere to the hand space representing wholly unrestricted movement for any and all hand and forearm orientations - the only condition would be that the subject's back and buttocks had the constant relationship to the " $R$ " point.

\section{METHODS}

Twenty-two male college students (ages 17-33) formed the study sample. In build they ranged from median to muscular; rotund and thin types were excluded. The more significant mean dimensions were: stature-175.7 $\pm 4.5 \mathrm{~cm}$ (69.4 in.); sitting height $-91.5 \pm 3.2 \mathrm{~cm}$ (36.1 in.); acromial height (sitting) $-61.3 \pm 3.2 \mathrm{~cm}$ (24.2 in.); and upper limb length (acromion to dactylion III--arm straight, horizontal, and forward ) $-72.8 \pm 2.9 \mathrm{~cm}$ (28.7 in.).

Our primary records (fig. 1) were a series of photographic negatives - time exposures in the dark-which showed the path of movement of a small light at the hand (i.e., over the "grip point") as it was moved by the subject. The subject sat facing the camera in a special seat and, for the first record, he moved his hand over a wire screen at arm's length so that it described a circuit at the extreme limit of movement. In his hand he held an appliance consisting of a screen grid and an adjustable hand grip (referred to later) which assured that the grip axis was maintained in some standard orientation throughout the circuit. Then the seat and subject were advanced a measured distance relative to the plane of the screen, and a new hand circuit was photographed The subject was moved forward progressively in this step-wise fashion and additional hand circuits were recorded for each position of the seat and subject until each level of the whole kinetosphere had been photographed. The photographic records provided a group of equally spaced frontal serial sections through the kinetosphere. From these, a variety of data could be derived, including three-dimensional models.

The seat on which the subject sat was of wood, and it had a back and a headrest. The basic plan was that of the Air Force fighter cockpit of the early 1950's. The seat was $15 \mathrm{in}$. deep and $11 \mathrm{in}$. wide; because of the narrow seat back, the subject's elbows and shoulders were unimpeded, thus the posterior range of the grip point was not artificially reduced. The seat was tilted $6^{\circ}$ to the horizontal. The back was 26 in. high, and it tilted back $17^{\circ}$ from the vertical. At the top of the seat back, an adjustable dental headrest was mounted. The position of the footrest and foot platform relative to the seat could be adjusted by oblique upward and forward movements as in the airplane cockpit, so that individuals of different heights could be accomodated comfortably. Through adjustments of the height of the foot platform, the vertical distance between eye level and heel was made a standard $39.5 \mathrm{in}$. for each subject.

As shown in figure 1 , several wire grids $(1 \times 2$ in. mesh) were suspended from an overhead horizontal bar parallel to the picture plane of the camera to provide a frontal reference plane behind which the hand could move. A large $5 \times 7 \mathrm{ft}$. mirror set at $45^{\circ}$-on the subject's left-showed a side view of the grid, subject and seat.

The hand appliance (fig. 2), which was constructed for the left hand only, con- 
sisted of a handle-a $30 \mathrm{~mm}$ aluminum rod-and a small rectangular orientation grid. Scotch-lite reflective tape was added to the vertical midline and the horizontal borders of the grid to enhance visibility in the photographs. Dental moulding compound was shaped about the aluminum rod to provide a good fit for the thumb, palm and fingers of the left hand; thus the handle could be grasped in only one way. An aluminum ball at the thumb end of the grip had a series of threaded taps by which the small rectangular grid could be attached at one or another of a number of selected angulations relative to the hand grip. When the grip was held firmly in the subject's left hand and the forearm, wrist and grip were aimed straight ahead, with the grip vertical, the grid was initially set upright in the frontal plane (i.e., $0^{\circ}$ ). After this initial adjustment, 7 other grid positions (fig. 2) were obtained by screwing the grid to the ball at other standard angulations. In each position the grid and the grip were oriented at a specific angulation to one another. When the grid



Fig. 1 Method for recording extreme movements of the "grip point" of the hand in the plane of the wire screens. The figure at the right is a $45^{\circ}$ mirror image of the subject shown front view. During a time exposure a flashing light at the level of the grip point marks out a path of movement. The hand grid assures a vertical hand grip orientation. Fixed reference lights lie over the sternum; other moving lights are attached to the shoulder and elbow. 


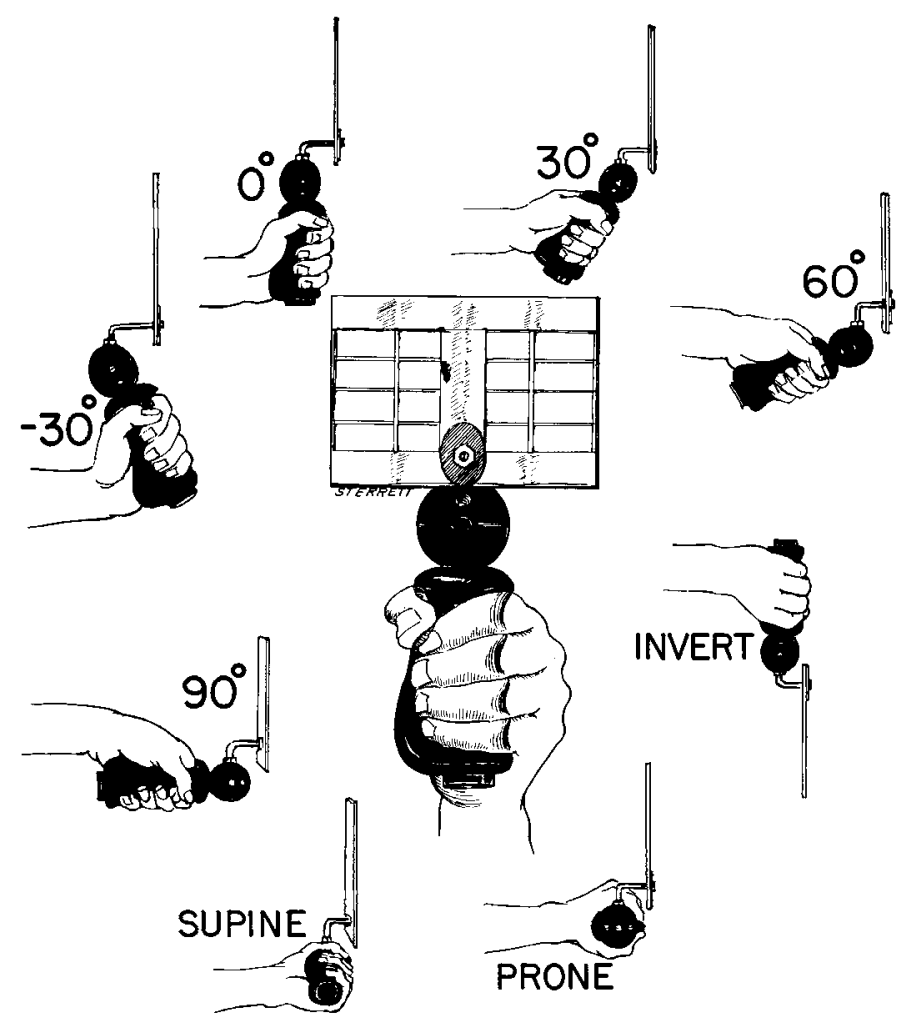

Fig. 2 Hand grip and reference grid designed to keep the hand in a fixed orientation while hand movements were recorded. The 8 standard hand orientations studied are illustrated.

was held upright in the frontal plane (for instance, behind and parallel to the hanging grids of figure 1), the hand grip axis of necessity assumed some fixed angulation to the vertical. Five grip orientations in the sagittal plane (relative to the room) were permitted and these were: $30^{\circ}$ back (i.e., $-30^{\circ}$; upper end of the grip directed backward and upward), $0^{\circ}$ vertical, $30^{\circ}$ forward, $60^{\circ}$ forward and $90^{\circ}$ forward (i.e., the grip was horizontal and directed forward). In adidtion to the $0^{\circ}$ position, three other positions in the coronal plane were permitted by the ball at the hand grip. These were the prone and supine positions and a vertical position with the thumb downward-the invert or $180^{\circ}$ position.

A $1 / 25$ watt neon glow lamp was adjusted to the hand grid, so that its position in photographic records lay at or near the center of the grip, i.e., the "grip point." Sometimes other lamps also were fitted over the shoulder and elbow joints. A flashing rate of 6 per second, controlled by an electronic system, allowed easy differentiation of traces when more than one appeared on the film. A Graflex camera at $15 \mathrm{ft}$. distance from the reference plane of the suspended wire grids included a field like figure 1. A red lens-filter transparent to neon light was fitted to the camera, and a low-intensity blue light that did not record through the filter was used for general illumination of the otherwise darkened room. Dark backgrounds were provided for both the direct and mirror-image views.

For the record-taking, the subject sat squarely against the seat back and headrest, and he directed his arm straight forward with the shoulder protruded and the grid of the hand grip held behind and parallel to the suspended reference grids. While the arm was in this position, the seat was moved forward or back until the 
distance between the grid plane and the " $R$ " point of the seat was as short as possible-a three-inch or less clearance was permitted for the movements of the hand grip. The actual seat-to-grid distance was measured and recorded. When this adjustment was made, the reference grid at the hand was 3 in. or closer to the zero grids.

The first photo record was taken with the neon lights flashing as the subject slowly moved his hand clockwise in the frontal plane-then counterclockwisethrough the widest possible complete circuit. The hand grid was to be kept constantly in its upright orientation just behind the reference grid; this was critical since a constant grip orientation was essential if the hand motion were to be strictly translational. In the faint blue light of the room, the camera operator could see both the direct and mirror-view of the subject; the mirror-view showed the reference grid edge-on, and any deviations from the frontal plane could be seen. Any sidewise tilting of the grid could be seen directly. If any significant deviations were seen, the camera operator could direct the subject to repeat the record. After practice runs in both the clockwise and counterclockwise directions, the camera was opened and the path of both circuits of the neon lamp was recorded. At some time during the movement, a speed-lamp (= strobe) flash was set off to illuminate the whole view including an instantaneous image of both the direct and side views of the subject (fig. 1).

When a new film (super XX, film pack) was in place for a second exposure, the seat and subject were moved a fixed standard distance (three or 6 in.) closer to the reference grid, and a new pattern of hand movement was photographed. After each exposure, the seat and subject were advanced by the standard distance until the subject no longer had space to move his hand between the reference grids and his body. One or another panel of the grid in front of the subject was then raised or, if they touched him, removed. Movements of the hand at the side of or behind the body were traced over a single grid at the left of the body.
Since the records were intended to show the range of hand motion, it was important that adventitious trunk movements did not augment the motion. Figure 1 shows a yoke of sheet lead lying on the sternum with flashing neon lights over the manubrium and xyphoid. Where the photo negatives showed that the lights had moved as much as $1.5 \mathrm{in}$. during the clockwise and counterclockwise movements of the hand, the record was later repeated.

The photo negatives for each subjectgrid distance were projected in an enlarger to exactly 1/5 natural size. Tracings of each negative were made on paper separately, including neon light paths as well as orienting landmarks and dimension marks in the background. Next, as a separate operation, a mean circuit was drawn in between the tracings of the clockwise and counterclockwise circuits of the neon light; this mean circuit was thereafter taken arbitrarily as the definitive record of "extreme" hand movement in the plane of reference.

Planimeter measurements of the area of each mean circuit were then made from the tracings. These areas were next plotted as ordinates on graph paper (fig. 5) with a spacing along the abscissa comparable to the distance between sections; the location of the "R" point and reference grid was also drawn on the graph. Two corrections were necessary before the graph was strictly accurate; first, the mean anteroposterior distance between the hand light and the reference grids (as seen side view, fig. 1) had to be measured; secondly, the distance between the light (or reference grid) and the grip point-different for each grip orientation-had to be added. After these corrections had been plotted relative to the reference grid position, the plot was properly related to the grip point. An accurate area-to-distance curve could now be constructed (fig. 5). The area under the curve, as measured by planimeter, corresponded (at one-fifth scale) to the volume of the kinetosphere.

In addition, through a treatment of moments along an antero-posterior axis (i.e., areas of sections $\mathrm{x}$ distances from a zero point) the fore-to-back distance of the centroid, or center of gravity, of the kineto- 
sphere could be calculated and located relative to the grid plane and to the " $R$ " point of the seat.

Next through the suspension of cardboard cutouts, the locations of the centers of gravity were found for two sectionsthat just directly ahead of and that immediately behind the kinetosphere centroid. The centers of gravity of the two sections were located relative to a vertical coordinate corresponding to the mid-sagittal plane of the subject and a standard transverse coordinate near the shoulder level; then tracings of the two sections were superimposed and, by appropriate "weighting," a new "mean" section contour with its center of gravity was drawn in for the correct antero-posterior distance of the kinetosphere centroid. We assumed that this section-centroid would have vertical and horizontal coordinates comparable to those of the whole kinetosphere. With this approximation, it became possible to relocate the centroid of the whole kinetosphere relative to the " $R$ " point of the seat-anteriorly, laterally, and vertically.

A convenient way of comparing kinetospheres involved the use of sagittal, frontal, and horizontal sections through the centroid. This required a reconstruction of contours from measurements derived from the sections. The technique involved first the marking of the horizontal foreand-aft projection of the centroid of a kinetosphere upon each tracing in a series of sections. Then, at points directly above and below the centroid on each section, the distances to the section outline were measured. These measurements were next plotted as ordinates on graph paper (above and below a horizontal line indicating centroid level); the horizontal spacing was comparable to that between sections. When the points were connected, the plot represented a sagittal section through a kinetosphere at centroid level. The " $R$ " point, kinetosphere centroid, and other points were added also. Comparable plots showing transverse measurements at centroid level permitted the development of a horizontal section through the kinetosphere. A coronal section through centroid level was determined, as mentioned above (previous paragraph), by a "weight- ing" of the contours of two section cutouts-the ones just anterior to and posterior to the centroid.

The three sections cutting the kinetosphere in mutually perpendicular planes that intersected the centroid could be interpreted as easily as three-dimensional plastic reconstructions; the shapes could be compared, by superimposing section outlines; the contours could be superimposed and summated to give generalized patterns for a group of individuals, or they could be grouped to show strophosphere patterns.

Actual three-dimensional reconstructions were made from tracings through representative kinetospheres. Much like the wax plate reconstructions of embryologists, these models were made from slices of styrofoam plastic $(12 \times 12 \times 0.6$ or 1.2 in.); the thicknesses of the plates of foam plastic were just $1 / 5$ of the three or 6 -in. distance that the subject was moved between records.

In the initial photography, each of the 22 subjects went through the procedures 8 times; each time represented a different hand orientation and hence a different kinetosphere. From each group of records (i.e., one kinetosphere for one subject), we had as working data: (1) a group of 7 or 8 (or more) frontal tracings of mean hand range having a known antero-posterior spacing, (2) plots representing sagittal, frontal and transverse sections through the kinetosphere at centroid level, and (3) area and volume data based on planimetric measurements.

Since the data relating to a single individual were of limited practical interest, our data were typically summated or averaged in some way. For numerical data, such as planimeter measurements of sections, kinetosphere volumes, and distances, individual records were simply averaged. Where shapes were involved, composite mean section contours were necessary. The sagittal, horizontal, or frontal plots (through a centroid) of different individuals, as mentioned above, were superimposed relative to the seat coordinants (and other landmarks in the original photographs) and traced in different colors, to avoid confusion, on tracing paper or on translucent plastic; centroid locations 
were indicated also. The mean centroid location for all of the similar kinetospheres together could be found through a consideration of their moments. After this point had been located, 8-10 lines were drawn radiating out from the common centroid to the contours of the superimposed colored tracings. Along each of the radiating lines, measurements were made of the distance from the centroid to each of the intersecting contours. These distances were then averaged to give a mean distance, and this was marked as a point on the radiating line. A mean contour could then be drawn through the points. In addition to the average contour, the distances of the individual contours from the average were measured along the radii, and the mean deviation was calculated. It should be noted that the plus and minus mean deviation rather than standard deviation has been used as a simple measure to compare the variability of one region of the space-shape with another; M.D. = $\Sigma(D / n)$.

In gathering and processing the data, utmost attention was paid to obtaining correct orientations and dimensions. For this reason, the results obtained from the material at one-fifth scale could be projected back to natural size with no appreciable loss of accuracy.

All our records were taken from the left hand. Since the two hands should have about the same range of movement, the mirror image is roughly comparable to a direct record. Thus, when right-hand kinetospheres are implied, they are simply mirror images.

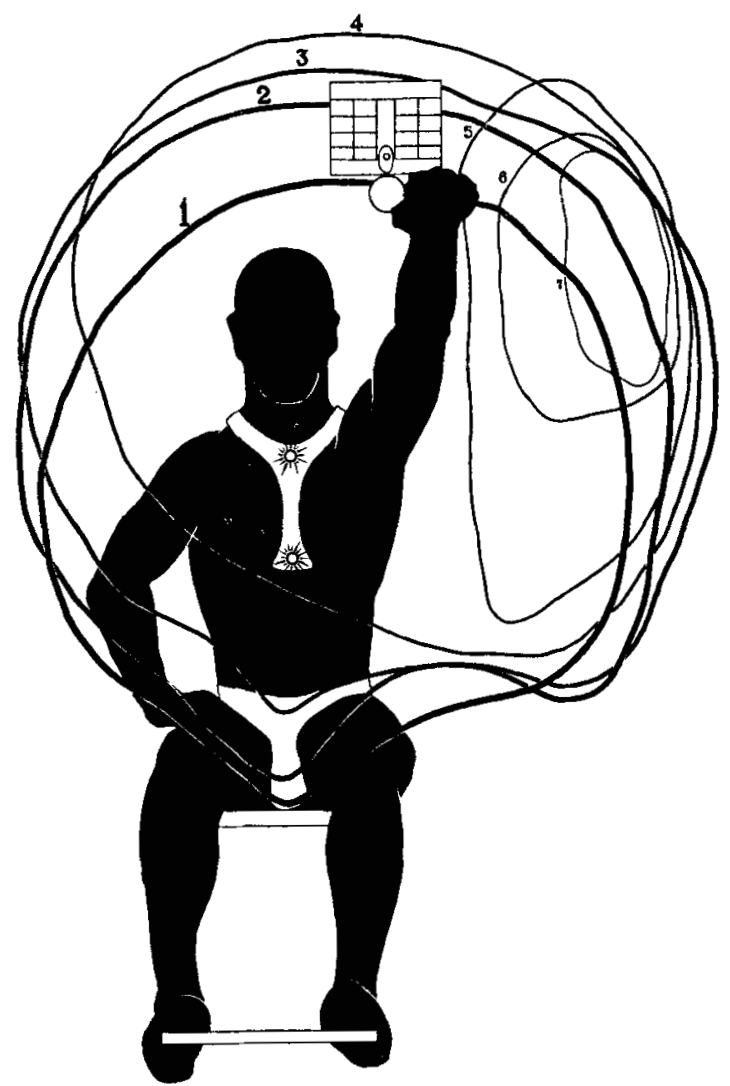

Fig. 3 Seven contour outlines show the range of movement of the prone hand over a series of frontal planes spaced at 6-inch intervals. The relative position of the seat and subject are shown also; the lights attached to the yoke over the sternum indicated whether or not trunk movement contributed to hand range. 


\section{RESULTS}

\section{Section contours and kinetosphere shapes}

Since the basic data for this study consisted of a group of mean tracings of frontal-plane serial sections through each of the 8 kinetospheres of 22 different men, the general character and implications of the sections themselves must be appreciated. The sections illustrated (fig. 3) represent the range of motion of the grip joint of the prone hand directed forward for one of our subjects.

\section{Superimposition of sections}

The sections were superimposed relative to both the midline of the seat and a transverse line (near shoulder level) through a landmark at camera height in the background of the original photo. One sees a series of 7 rounded or irregular closed outlines which varied in size and orientation relative to the subject's body. The contours in this instance represented sections at a 6-inch spacing through the kinetosphere. The first section, that farthest forward from the body, was ordinarily roughly circular. If the subject could scarcely reach the grid, the diameter was small; in a larger contour, the first section could, as shown, have an irregular lower boundary over the knees. The limits of forward movement for the maximally protruded shoulder were determined by the fact that the hand, because of the obliquity of the arm in a wider circuit, would move away from the plane of the hanging reference grids.

As the subject-to-grid distance was shortened, the size of the circuits increasedparticularly in the upper range. As the seat-grid distance was further reduced, ligamentous restraints to wrist abduction on the test-limb side and limits to adduction on the far side defined medial and lateral boundaries for movements of the prone hand. At the same time, a lower limit was imposed by contact with the knees or thighs. An upper limit was determined by maximum shoulder elevation and by the tendency of the raised limb to retract from the grid plane. The limitations mentioned restricted movements to broad, elliptical contours, except where knee and thigh contact intruded. The highest contour came to lie above the left shoulder. At the next section, there was not room for forearm and wrist movement between the body and the reference plane. This limitation to hand movement produced a definite posterior surface to that portion of the kinetosphere in front of the trunk region. Until the trunk hindered movement, knee and thigh contact and the maximum amount of abduction, flexion, extension, or adduction permitted at the wrist joint were the limiting features to movements in the coronal plane.

After trunk contact with the wrist and forearm, the only territory free for additional limb and hand movement was lateral to the trunk on the test-limb side of the body. These contours became narrow vertical ellipses, with the upper pole tending to deviate toward the head. Movement was restricted on the left because of inability to increase wrist abduction. Other boundaries were due to limited wrist flexion (above), to the amount of wrist extension permitted (below), and to body contact (medially). At the extreme posterior range, shoulder retraction and elbow flexion reached a maximum. It should be noted that the narrow seat back used did not restrict movement of the shoulder and elbow and that the hand could move about at the side of and even slightly behind the body without artificial contact restraints.

\section{Total shape}

Although serial sections are informative, the three-dimensional character of the kinetospheres can be shown initially to better advantage by reconstructed plastic models, such as that in figure 4 . The model represented a smoothed composite of the mean space envelope for the prone hand. The principal bulk of the kinetosphere lay in front of the trunk and above the knee and thighs, extending a full head higher than the mean sitting height, and its maximum height was again above the left shoulder. The kinetosphere bulged medially and laterally-mainly laterally-and it had a "wing" projecting to the left and backward to a point a little behind the seat $\mathrm{R}$-point. For the prone hand, much of the restraint medially and laterally was caused 


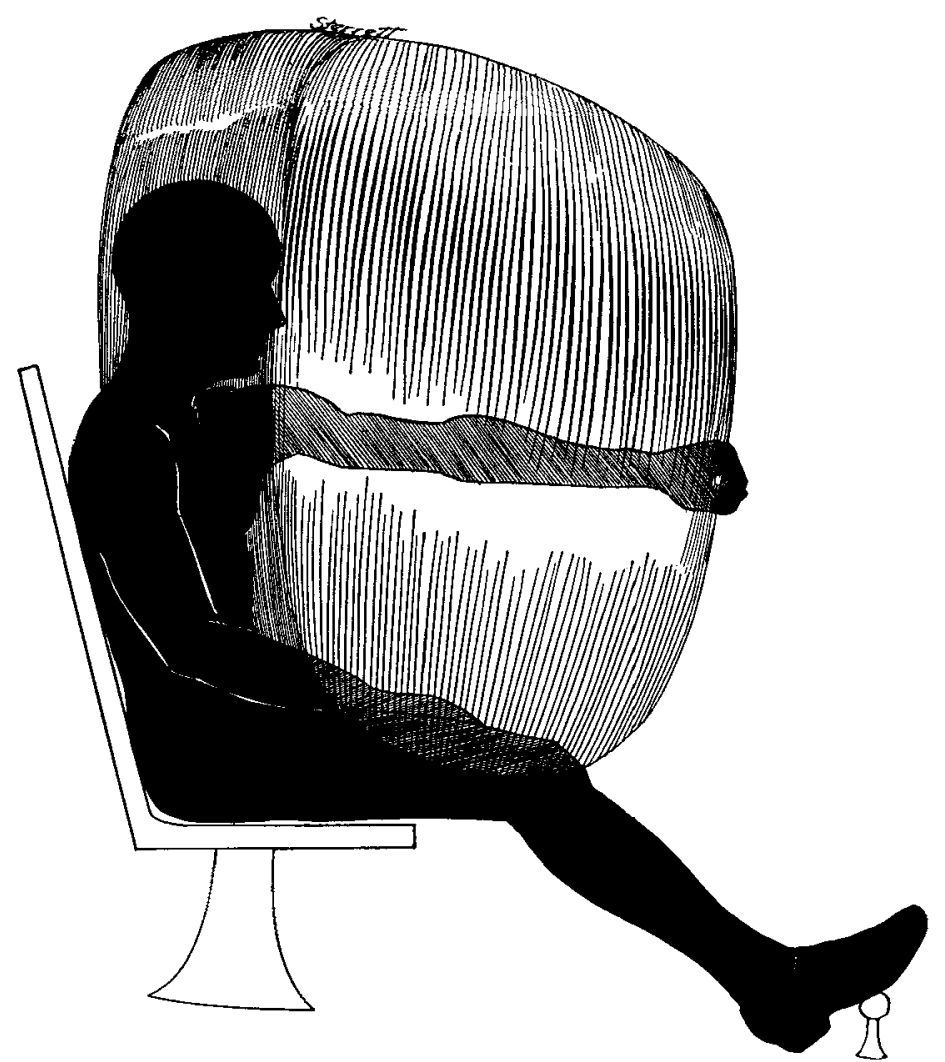

Fig. 4 Medial view of a three-dimensional reconstruction of the mean kinetosphere for prone left hand shown in relation to the seat and an average size subject.

by the limitation of wrist adduction and abduction. The larger range of wrist flexion and extension was less restrictive on the hand at the upper and lower limits of the hand range.

When the grip axis is held vertically instead of prone, the limit due to wrist abduction affects the lower kinetosphere range rather than the lateral side. When the grip axis is supine, the abduction limit affects the medial side of the space. Similarly, flexion, extension and adduction limits of the wrist affect different parts of kinetospheres according to the angular position of the grip axis and the orientation of the specific restraining ligaments.

Each of the 8 kinetospheres studied was similar to the extent that the major bulk of the space was above the thighs and ahead of the trunk and that each had a wing to the side of the body; nevertheless, each had characteristic differences in di- mensions, in height relative to the seat, in size of wing or in slope of contour in one region or another. These differences were basically controlled by the kinematics of the upper limb joints and segments under the restrictive conditions of holding the hand grip in a constant orientation.

Factors affecting kinetosphere shape

When confronted with a three-dimensional model of a kinetosphere, people sometimes suggest that the subject should be able to reach higher, more to the side or more between the thighs. This is true, but for the average test subject, it is true to a marked degree only when he fails to maintain the standard hand orientations. The conditions for defining a given kinetosphere no longer exist when a subject appreciably changes the grip orientation or the direction of hand "pointing." 
The range of translatory movement permitted the hand by the upper limb joint systems was limited in different directions either (1) by contacts with the trunk, thighs, or knees, or (2) by a restriction of movement in one or more critical joints in consonance with the hand having a fixed orientation irrespective of where it lay within a kinetosphere. The joint limitations were just as real as the body contacts. When the hand moves about while it maintains a fixed orientation, the wrist, the forearm, the elbow, and the claviscapular mechanism of the shoulder, which lie between the hand and the trunk, must adjust to the movement within the limits of their individual joint ranges. In one part of the hand range, depending upon the orientation of the hand in translatory motion, further movement may be limited by the inability to abduct the wrist further while in another region a lack of additional wrist extension may be the restricting factor. Shoulder and elbow joints may limit movement in the same way. The boundaries of each kinetosphere thus are determined by a distinctive type of limitation.

Linear dimensions of the upper limbs also are metrically correlated with the extent of hand range, thus the longer-limbed subjects were able to reach farther upward, downward, laterally, and medially across the trunk, as well as farther forward and backward. In general, tall, thin men with more flexible joints had greater hand ranges (Dempster, '55a), and smaller, heavier men with less joint flexibility produced kinetospheres of reduced dimensions.

Functional body contact must be understood as contact with any part of the arm, elbow, forearm, hand, or hand grip. Arm and forearm contact in one or another hand orientation affects the closeness of the grip point to the front and side of the trunk, to the groin region, to the medial sides of the thighs, to the opposite side of the thighs, etc. These contacts imply functional limits to hand range; since the grip point lies in the middle of the fist, it never can be closer to the body at any point than perhaps three inches.

Other factors having an effect on kinetospheres related to the psychology of the test individuals. If the subject did not conscientiously attempt to reach the very maximum of the translatory motion, the kinetosphere boundaries proved false. In the taking of records by the procedures outlined, it soon became apparent that overly eager subjects tended to bend the trunk or twist the hand position to get unreasonably large ranges. Neon lights attached over the subject's sternum, however, gave an indication of the degree of this defect. Where the records showed an unusual amount of trunk movement, the records were discarded and repetitions were made. Contrarily, lazy subjects tended not to exert themselves. Careful attention to procedures and repetitions, in certain instances, undoubtedly reduced this source of error to a minimum. The averaging procedures employed smoothed out most of these individual differences. Measures of variability, which will receive attention below, clearly involved psychofunctional factors as well as strictly kinematic factors.

The reference grid introduced an extrinsic, non-functional factor; it extended $5 \mathrm{in}$. on either side of the center of the ball and $7 \mathrm{in}$. beyond. The contact of the grid with the body was not a significant contaminant for the supine or the sagittal series of kinetospheres. Figure 3, however, suggests that if the reference grid had not been between the hand and the side of the body the medial border of the "wing" might have extended inward more. Overall kinetosphere volume, in this instance however, would be reduced only in the region at the side of the body. The invert kinetosphere was more seriously affected; if the grid were to be seen by the subject unobscured by his hand and forearm, the grid must lie between the thighs and hand. The regions above, forward, to the sides, etc. were not affected by grid error. The inclusion of partially contaminated prone and invert data in this paper may be justified since these extrinsic contact errors are on the body side of the kinetosphere rather than on the outer ranges; accordingly the errors have little effect on the problem of practical work space design. Questionable features, however, will be kept before the reader. 
The greatest discrepancies from subject to subject related to the kinetosphere region nearest the thighs, pelvis and lower trunk. Frequently the subject did not move his hand as closely as possible over and between the thighs; consequently, the clockwise and counterclockwise circuits were less well duplicated in this region than in the rest of the circuit. The mean curves drawn in consequence appeared to be displaced upward by several inches. The subjects sometimes moved their feet from the foot rest and, by planting the feet flat on the floor area ahead of the seat, raised

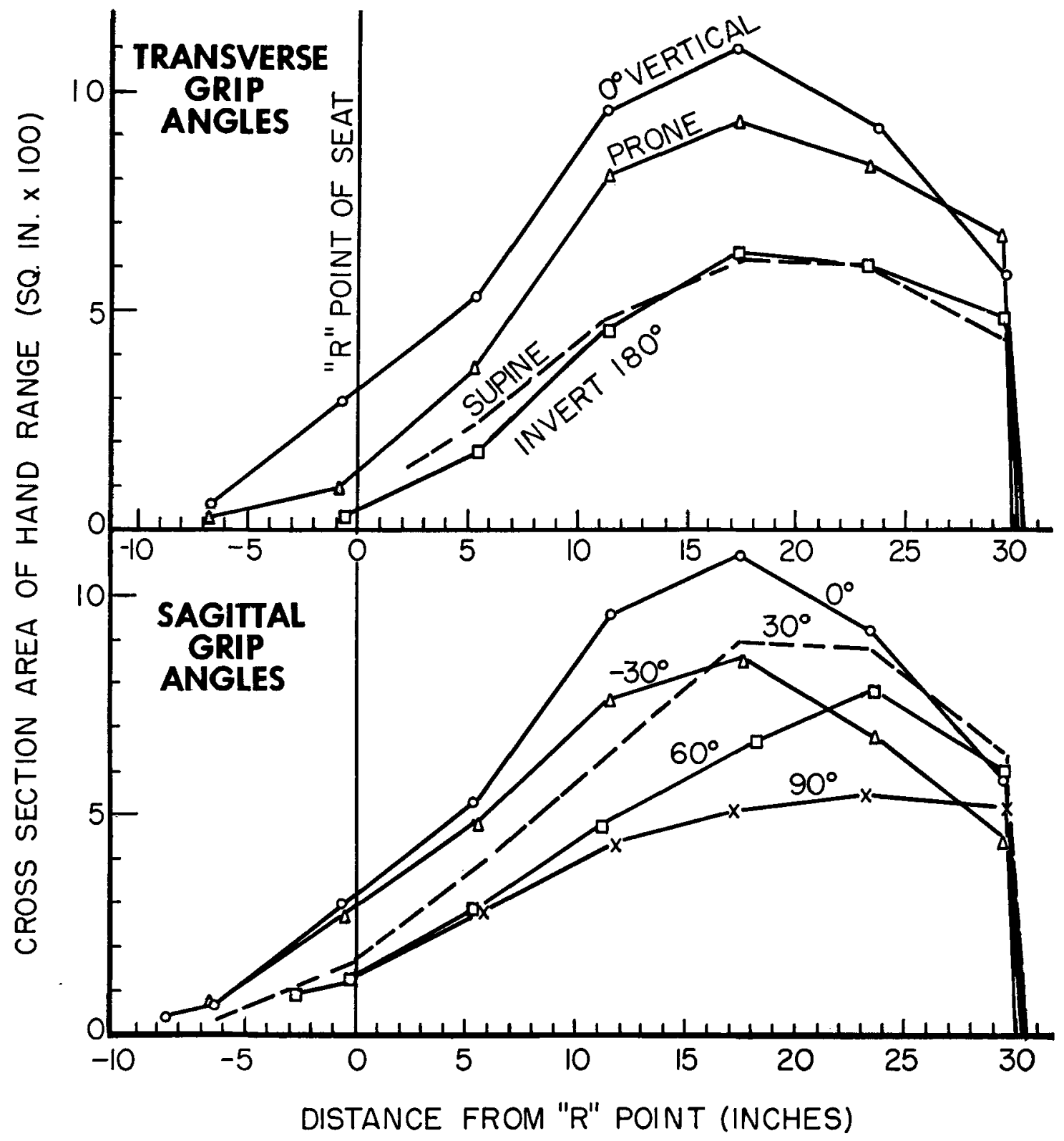

Fig. 5 Two series of plots showing the panel area available to the grip point of the left hand for transverse planes at different distances from the " $R$ " point of the seat. 
thigh height; in such instances the lower borders of kinetospheres would be raised still further. Practically, however, these discrepancies do not affect the exterior dimensions of the work space; they would affect only the region adjacent to the trunk and thighs. Kinetosphere volumes, centroid height and the height of common hand areas, etc., would be biased to a degree, but in a predictable direction. Except for the invert kinetosphere as mentioned, there is no reason to expect that the bias should not be the same for all hand orientations.

\section{Area to distance plots}

The curves in figure 5 are plots of the areas of cross-sections through kinetospheres relative to the distance of these cross-sections from the R-point of the seat. Each of the curves refers to a different hand orientation and is an average for the 22 subjects. The upper figure represents area/distance plots for transverse orientations of the hand grip and the lower shows plots for the sagittal hand grips. These two plots show, then, the relative maximum range of the hand (i.e., grip point) over vertical-transverse planes placed at intervals from 30 in. ahead of the R-point to 9 in. behind. If a worker such as a telephone operator were to be seated in front of a vertical panel, the area plots suggest the relative area of hand-panel contact at different seat-topanel distances.

At the farthest extent of arm reach ( \pm 30 in.), the cross-section within reach increased rapidly from zero to $400-700 \mathrm{sq}$. in. Areas at distances closer to the seat then built up to a maximum (600-1000 sq. in.) for the best distances from the R-point and then fell off rather rapidly. The curves for $0^{\circ}$, prone, $-30^{\circ}$, and $60^{\circ}$ rose rather sharply to a maximum; those for $90^{\circ}$, supine, invert, and $+30^{\circ}$ built up more gradually. Since the size of the hand grip introduced a bias (discussed above), the prone range should be slightly higher at the side of the body (i.e., +12 in. to -7 in. in relation to the $R$-point). The more anterior range for invert should read higher. All of the curves fell off rapidly inside the +12 in. level. The $90^{\circ}$ curve showed fairly constant panel areas of $\pm 500 \mathrm{sq}$. in. between 15 and 30 inches from the $R$ point; closer to the R-point, the areas dropped off rapidly.

In general, the areas indicated by the $0^{\circ}$ curve were larger than the others; $0^{\circ}$ followed by prone, $+30^{\circ},-30^{\circ}$, and $60^{\circ}$ had maximal areas in the 800-1000 sq. in. range. The curves for invert, supine, and $90^{\circ}$ were definitely less.

The maximum area covered at a given distance from the seat varied according to hand orientation. Most of the curves showed maximal cross sectional areas at 17-20 in. from the R-point; for the $60^{\circ}$ to $90^{\circ}$ hand orientation, the maxima were closer to 24 in. from the R-point. These section-to-R-point distances referred to the horizontal distance from the R-point to the grip point; when in a practical work-place situation, objects in the fingers and hands protrude anterior to the grip point; due allowance should be planned for this additional dimension.

\section{Kinetosphere volumes}

By measuring the areas under the area/ distance plots with a planimeter, it was possible to obtain the volume of any given kinetosphere. Thus, we had a further criterion for demonstrating the characteristics of different hand grip angles. These volumes are presented in table 1 , which

TABLE 1

Average kinetosphere volumes for the study group

\begin{tabular}{cccc}
\hline $\begin{array}{c}\text { Hand } \\
\text { orientation }\end{array}$ & Volumes & $\begin{array}{c}\text { Hand } \\
\text { orientation }\end{array}$ & Volumes \\
\cline { 2 - 4 } & cu. in. & & \multicolumn{1}{cc}{ cu. in. } \\
$-30^{\circ}$ & 19,990 & $90^{\circ}$ & 13,040 \\
$0^{\circ}$ & 24,630 & Supine & 13,180 \\
$30^{\circ}$ & 19,940 & Prone & $20,670(+?)$ \\
$60^{\circ}$ & 13,030 & Invert & $12,920(+)$ \\
\hline
\end{tabular}

shows the kinetosphere volume for 8 hand positions.

Attempts were made to correlate linear dimensions of the subjects and goniometric data on the ranges of joint flexibility for the upper limb with the volumes of kinetospheres of individuals; these showed a general correlation between volume of the work area and both body size and the amplitude of joint movement. Neither standard anthropometric measurements nor measurements of joint range alone, however, presented the whole story since individuals differed notably. Large men 
with low joint flexibility or small men with greater joint ranges showed no consistent volume patterns.

\section{Kinetosphere sections}

The illustrations of figures 6 and 7 represent averaged sections of the 8 hand kinetospheres for the test subjects. In each instance, the kinetosphere is correctly placed relative to the " $R$ " point of the seat; thus shapes, centroid positions, etc., can be compared relative to the seat. For each kinetosphere, the three sections cut through the mean centroid location for the 22 men; the small crosses show the location of the mean centroids relative to the seat. The sections are perpendicular to one another; for each set of three sections the figures show, from left to right, a transverse, a coronal, and a sagittal section through the centroid. Patterns for both right and left hands are shown in the top (transverse) and front (coronal) view; these represent in reality a direct and mirror image of the left side kinetospheres.

The earlier section on technique indicated how the centroid of a kinetosphere was obtained. The centroid or center of gravity for a given kinetosphere has a specific location above, ahead of, and to the side of the " $R$ " point of the seat. It is the mean center of all the possible grip point positions for the given grip orientation-the point from which the hand may on the average, move farthest in all directions. Except for the $60^{\circ}$ and $90^{\circ}$ kinetospheres (figs. 6 and 7 ) where it is low, the centroids for the different kinetospheres lie above shoulder height, lateral to the shoulder and behind the knee. (The locus of the invert centroid, which was influenced by hand-appliance contacts, is pictured too high by perhaps $2 \mathrm{in}$; if the lower contour of the original frontal sections were to be lifted by 5 in., the centroid would be elevated 2 in.) Each location is distinctive according to kinetospheres, but there appears to be an underlying similarity. Figure 8 implies that each centroid is an expression of the hand position that results when each upper limb joint is fixed at the mid-range of its joint amplitude. The specimen illustrated was a special joint-ligament dissection; each joint between the clavicle and wrist was anchored at the mid-range position for each type or degree of freedom of joint motion permitted (joint range data from living subjects, Dempster, '55a).

In spite of the general similarity in contour of the top views, a number of differences can be seen. From $0^{\circ}$ to $90^{\circ}$ (sagittal grip orientations), there was a marked decrease (fig. 6) in both the size of the kinetosphere and in the overlap of right and left hands. In addition the midline region of the kinetosphere moved farther and farther from the body. Although the centroid of each of the 8 kinetospheres was in approximately the same position, anterolateral to the seat, there was again some variation. From $0^{\circ}$ to $90^{\circ}$, the centroid moved progressively farther out to the side. The $0^{\circ}$ centroid was slightly closer to the " $R$ " point of the seat, but the others were at about the same anteroposterior distance. Lateral reach was approximately the same for all the sagittal hand positions. The same held true for the distance back that the subject could reach. The kinetosphere for $-30^{\circ}$ was generally intermediate to $0^{\circ}$ and $+30^{\circ}$ in size, in overlap of right and left hands, in centroid position, and in proximity of the kinetosphere to the body at the midline.

In the transverse hand positions (fig. 7), kinetosphere dimensions were less for supine and invert than for $0^{\circ}$, in fact the smaller kinetospheres were about the same as the $90^{\circ}$ kinetosphere; that for the prone hand approximated the size of the $-30^{\circ}$ and $+30^{\circ}$. The amount of right-left overlap increased and the distance between the kinetosphere and the body in the midline region decreased to $0^{\circ}$; the supine kinetosphere contrasted markedly in both respects. The lateral position of the centroid remained about the same from invert to $0^{\circ}$, but it was far more lateral at supination (approximating that of the $60^{\circ} \mathrm{ki}$ netosphere). The distance of the centroid from the " $R$ " point decreased through invert and prone to $0^{\circ}$, though it increased again at supination. Hand reach laterally and posteriorly toward the "wings" of the kinetosphere was reduced for the invert, prone, and supine hand positions, although lateral reach was slightly greater for the invert kinetosphere. (The reduced medial 

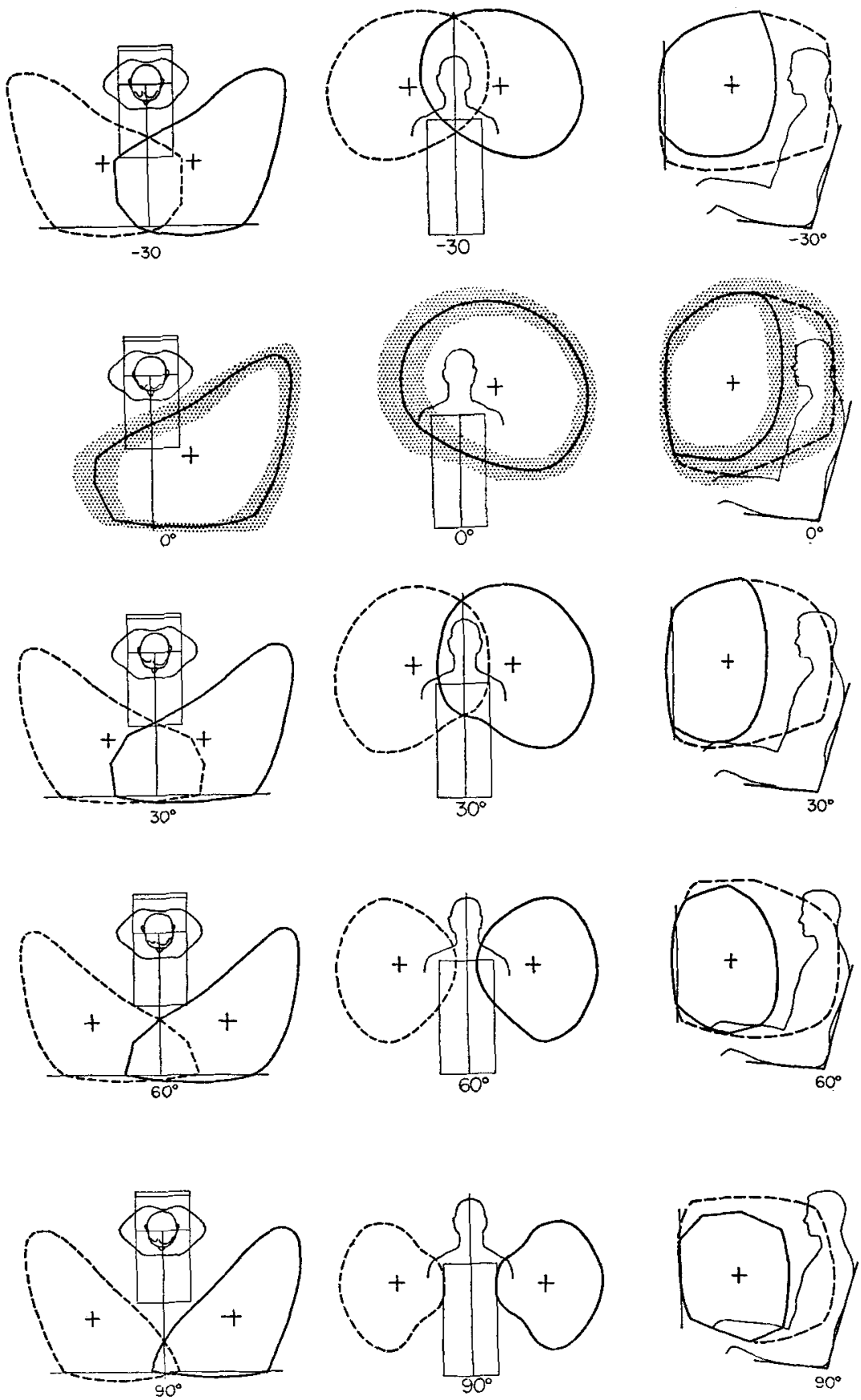

Fig. 6 Top, front and left side view of sections that pass through a series of kinetospheres at centroid level. Each successive transverse row represents $30^{\circ}$ additional tilt to the hand grip in the sagittal plane. The right side areas are mirror images of the left side. The shaded halo for the $0^{\circ}$ kinetosphere illustrates the mean deviation for different regions of the contour. A plus sign shows the location of the kinetosphere centroid. 

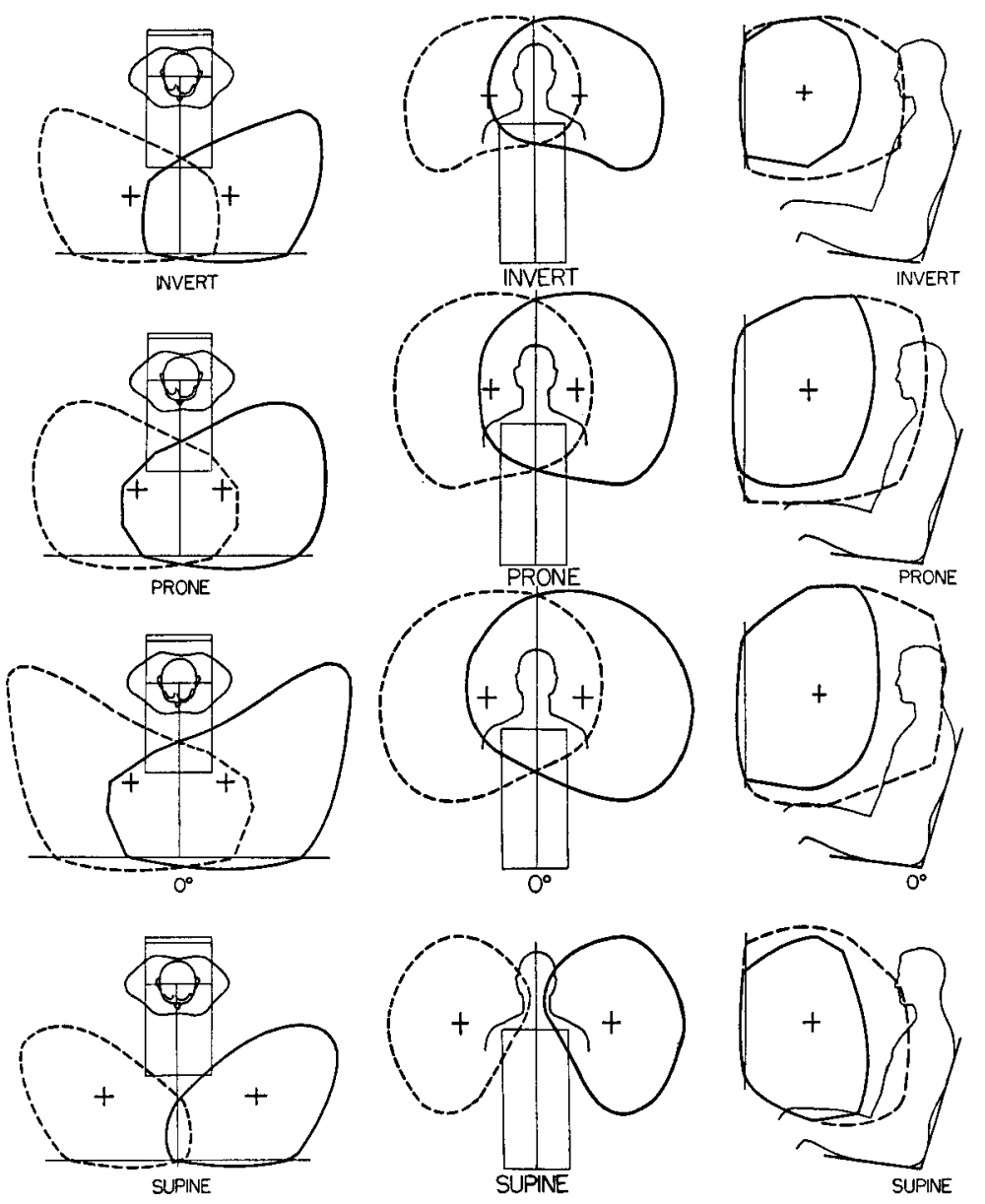

Fig. 7 Top, front and side views of sections through kinetospheres representing transverse changes in the grip axis.
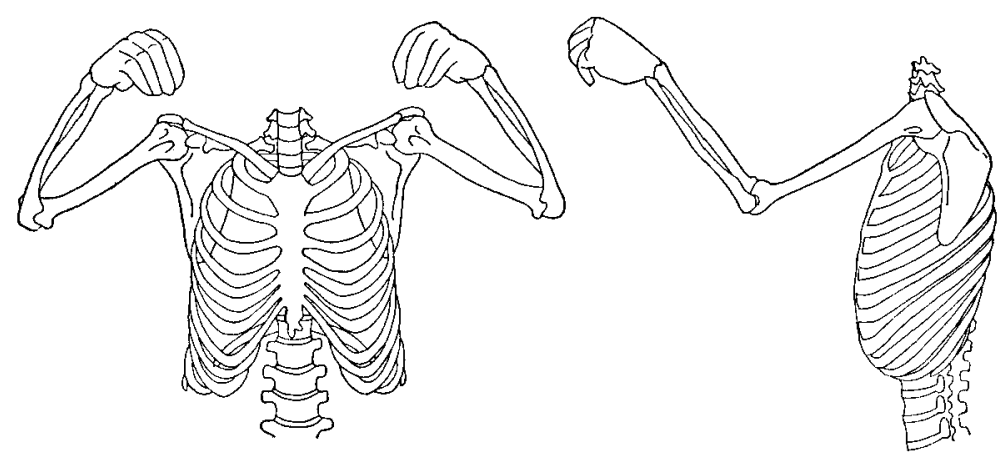

Fig. 8 A skeleton-ligament preparation showing the hand position that results when the sternoclavicular, the shoulder, the elbow, the forearm, and the wrist joint are fixed at their mid-range positions. 
border of the wing for the prone kinetosphere was in part artificial because of hand grid interference.) Contrary to the sagittal grip positions, the transverse grips, other than $0^{\circ}$, did not allow the average subject to reach back posterior to the " $R$ " point.

The front views of the kinetospheres demonstrated about the same sequences and variations as the top views in regard to size, reach, and overlap. There was, however, no overlap at the centroid level for supination, $60^{\circ}$, or $90^{\circ}$; the overlap region was farther forward. From $-30^{\circ}$ to $90^{\circ}$ (grip orientations in the sagittal plane), there was a marked decrease in centroid height, which was below the shoulder at $60^{\circ}$ and $90^{\circ}$; no clear sequence was found in the transverse plane. The centroid heights for invert, $0^{\circ}$, and prone were above the shoulder in that ascending order-invert was artificially high because of hand grid interference; that for supination was right at shoulder level.

In the side views of the kinetospheres, the solid line represented a section through the centroid; the dashed line indicated the maximum contour to the side of the centroidal section-through the "wing." The main feature to be noted here is the vertical dimension of the lateral extension or "wing" of the hand kinetosphere. In the side views showing $-30^{\circ}, 0^{\circ}$, and $+30^{\circ}$, the lateral projection extended below the main body of the kinetosphere, but not above; at $60^{\circ}$ and $90^{\circ}$, it extended both above and below. For the transverse grip orientations, the lateral extension was again lower for invert and supination than for $0^{\circ}$. The respective heights of the kinetospheres themselves again were revealed in the side view; the lower border of the invert kinetosphere would appear to be too high. It may also be noted again that transverse hand orientations do not permit much posterior projection of the kinetosphere.
Surrounding the outlines of the $0^{\circ} \mathrm{ki}$ netosphere in figure 6 are halos which represent the mean deviation of the 22 subjects of the test sample. The $0^{\circ}$ kinetosphere was the least variable of the kinetospheres from region to region and from subject to subject. In addition to mean deviation, standard deviations were computed for superimposed horizontal and sagittal section contours of the 8 kinetospheres of the 22 subjects. The variability relative to the mean contours was measured in 6 places along radiating lines from mean centroid to the contours. Measurements were made along an antero-posterior line through the mean centroid and along lines through the centroid at equivalent $60^{\circ}$, and $120^{\circ}$ angles to the right and left; these lines cut the contours at 6 points along their circumference. The standard deviation of these measurements, as computed, gave some measure of the relative variability of the kinetosphere contours relative to one another. The values of the standard deviation and of the range which included $90 \%$ of the hand positions (in parentheses; i.e., 5th-95th percentiles) are shown in table 2. This tabulation shows that the $0^{\circ}$ kinetosphere was least variable, that the $-30^{\circ}$ and the $+30^{\circ}$ kinetospheres were slightly more but similar in variability, and that the $60^{\circ}$ and $90^{\circ}$ kinetospheres were increasingly variable-the $0^{\circ}$ was about $60 \%$ as variable as the $90^{\circ}$ kinetosphere. The prone kinetosphere had a slightly larger standard deviation than the $-30^{\circ}$ and $+30^{\circ}$ kinetospheres, the invert hand orientation had more, and the supine was the same as the $+60^{\circ}$ kinetosphere. These values in themselves are of little importance, but there are significant implications relative to the placement of hand controls for the seated operator. Because of the variability between subjects, more critical placement of controls in the work place is necessary when planned for the $90^{\circ}, 60^{\circ}$, and supine positions of the hand than for

TABLE 2

\begin{tabular}{|c|c|c|c|}
\hline S.D. & $90 \%$ Range & S.D. & $90 \%$ Range \\
\hline $\begin{array}{r}-30^{\circ} \pm 3.2 \mathrm{in} . \\
0^{\circ} \pm 2.8 \mathrm{in} . \\
+30^{\circ} \pm 3.3 \mathrm{in} . \\
+60^{\circ} \pm 4.2 \mathrm{in} .\end{array}$ & $\begin{array}{l}( \pm 5.3 \text { in. }) \\
( \pm 4.6 \text { in. }) \\
( \pm 5.45 \text { in. }) \\
( \pm 6.95 \text { in. })\end{array}$ & $\begin{array}{ll}90^{\circ} & \pm 4.7 \mathrm{in} . \\
\text { Supine } & \pm 4.2 \mathrm{in} . \\
\text { Prone } & \pm 3.5 \mathrm{in} . \\
\text { Invert } & \pm 3.8 \mathrm{in} .\end{array}$ & $\begin{array}{l}( \pm 7.7 \text { in. }) \\
( \pm 6.95 \text { in. }) \\
( \pm 5.7 \text { in. }) \\
( \pm 6.75 \text { in. })\end{array}$ \\
\hline
\end{tabular}


the $0^{\circ},+30^{\circ},-30^{\circ}$, and prone hand orientations.

\section{Strophospheres}

When sections through a related series of kinetospheres were superimposed to produce a strophosphere, a larger space was outlined than that for any individual kinetosphere (figs. 9 and 10). The kinetospheres were superimposed relative to the seat and "R" point. Figure 9 shows a strophosphere which defines hand position with three degrees of translatory freedom of motion plus one degree of rotation in the sagittal plane through angulations of $-30^{\circ}$ to $+90^{\circ}$. Figure 10 shows another strophosphere in which the hand grip rotates through the transverse plane (from supine through $0^{\circ}$ and prone to $180^{\circ}$ invert), in addition to the usual freedom for translatory motion. In both figures, the trends that were noted earlier when separate kinetospheres were compared can be seen.

The size of the hand space for the $0^{\circ}$ orientation decreased systematically in several respects through the sequence $0,-30$, $+30,+60$ to $+90^{\circ}$. The postero-medial side of the strophosphere, i.e., toward the subject, shifted forward with each new hand orientation to reduce kinetosphere size. The wing decreased slightly, and the region of right-left overlap decreased markedly. Furthermore, the rear of the overlap area came to lie farther and farther from the body. The relative height of the upper and lower contours, including those of the wing, came to lie lower and lower through the series: $0,-30^{\circ},+30,+60$, and $+90^{\circ}$. Both the frontal and sagittal sections showed this sequence.

Similar transitions were shown for the transverse series of kinetospheres. The supine kinetosphere occupied a small part of the strophosphere. Its height was low, the shape was globular, and the wing was reduced in size. With the vertical $\left(0^{\circ}\right)$ hand orientation, the wing, the medial spread, and the right-left overlap increased to a maximum; the height of reach increased notably. For the prone hand, both the wing and the amount of right-left hand overlap were somewhat reduced. These trends continued further for the invert hand orientation $\left(180^{\circ}\right)$.
The strophosphere plots emphasized differences due to hand orientation, but, more importantly, they pointed to common features in a new way. The horizontally shaded area of figure 9 shows the space common to all vertical hand orientations; similarly, figure 10 shows the common space for all transverse orientations. For the sagittal hand orientations, the side-toside, and especially the up-down extent of the common region was reduced; the posterior extent of the strophosphere wing, including the common region extended back to the " $R$ " point. For the transverse hand orientations, the common hand space is short of the " $R$ " point by about 12 in.; it corresponded most nearly with the region within reach of the supine hand, but its lower range was less extreme.

The dots shown in figures 9 and 10 show the location of the centroids of the kinetospheres that were grouped in each of the strophospheres. In general they form graded sequences from kinetosphere to kinetosphere; they fall mostly above the distal part of the thigh, to the side of the shoulder and above the shoulder. The invert centroid (fig. $10 ; 180^{\circ}$ ) may, for technical reasons, be shown too high.

The region common to both the sagittal and transverse orientations of the hand, as seen in frontal and sagittal sections (fig. 11), was only slightly reduced from the size seen in the separate strophospheres. In horizontal section, the common area for the 8 hand orientations studied was reduced near the body and in the wing; the posterior extent of the common area of the wing was about 6 inches ahead of the " $R$ " point.

The common region (fig. 11--heavy stippling) was roughly 15 inches wide, 1618 inches high, and 18-24 inches deep; it lay obliquely, and its maximum anteromedial to posterolateral extent was about 30 inches with a perpendicular breadth of 18 inches at the maximum dimension. The orientation to the seat, to the " $R$ " point and to a man with the dimensions of our average subject, is shown; the body size shown is a composite based on tracings of photographs of the 7 subjects in our sample who most nearly corresponded to the average in sitting-height, sittingacromial-height and stature. The right-left 
overlap was negligible and far forward; most of the space was lateral to the shoulder region. It extended from nose to waist level and from the line of the chest forward to the extent of maximum hand reach. Within such a range, the forwarddirected hand could supinate or pronate through some $270^{\circ}$ and could rotate in the sagittal plane to about $120^{\circ}$; presumably, movements about a horizontal transverse wrist axis for various degrees of pronation and supination also should have been possible throughout most of the region.

Our figures have defined the region par excellence for the positioning of hand controls to be operated by one hand. Within this range there may very well be regions of preference, or regions of greater or lesser strength, or regions better correlated with precise or with gross movements, or regions more central relative to the visual field. Further study in this respect should have value practically. (For instance, a separate study on the mechanics of strong two-handed pulls for the seated operator (Dempster, '58) has shown that irrespective of the position of the hands, the pull vector is always (except for weak pulls) directed toward the midsternal region; the implication is that when levers and handles are placed in the work area, the direction of pull be planned as intersecting the sternum.) Regions outside the common range will not permit completely free movements of the hand. Closer study of the fig-

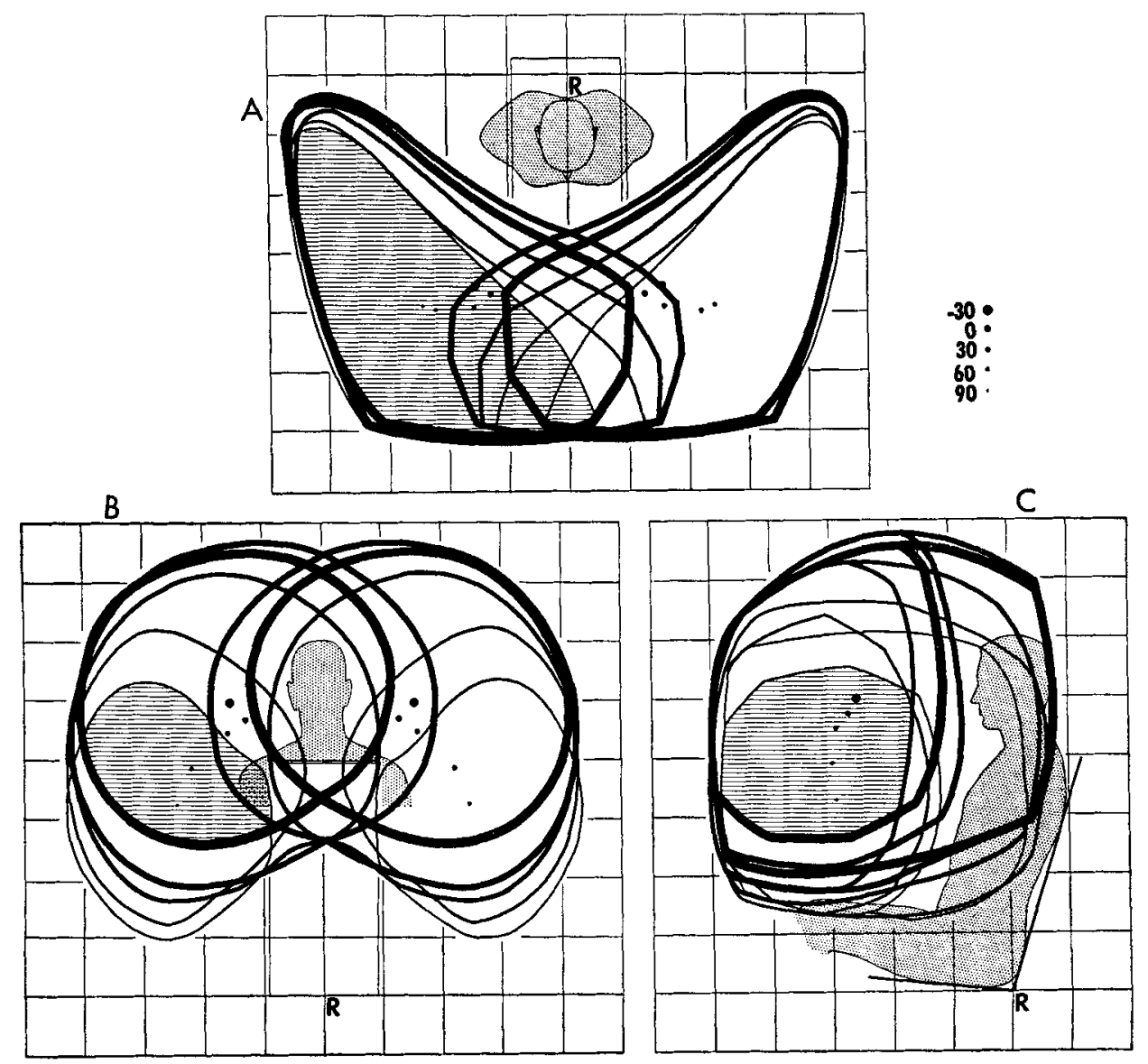

Fig. 9 A group of superimposed kinetospheres representing changing grip orientations in the sagittal plane enclose a strophosphere. Horizontal shading, the region common to each kinetosphere; dots, centroids of the several kinetospheres. 
ures showing the common region of the strophosphere in relation to specific work operations might suggest certain restrictive hand positions not be used; the common space for other hand positions would be larger than if the restrictive positions were included.

A centroid for a given hand orientation implies the most central position within a kinetosphere. It is the least restrained position, or mean average position, for the given hand orientation relative to the whole system of limb joints. As in the ready or defensive position of the fists in boxing, the centroids (dots, figs. 9, 10 and 11) represent a sort of mean starting position for hand movements toward the limits of the reach in any direction. The cluster of centroids representing the different hand orientations studied should have similar implications for the combined strophospheres or ergospheres.

The centroids are shown in figures 9 , 10 and 11 as clusters of points relative to the contour of an average-sized man. The centroids as seen from the side view were more or less vertical within a range of 15-19 in. from the " $R$ " point; from above, the centroids extended from side to side in a band 7-15 in. from the midline; the front view shows the points extending in an oblique direction from above and medially ( $30 \mathrm{in}$. above the " $R$ " point of the seat and $7 \mathrm{in}$. from the midline) to a lower and more lateral point (15 in. from the midline and 19 in. above the seat " $R$ "

\section{B}
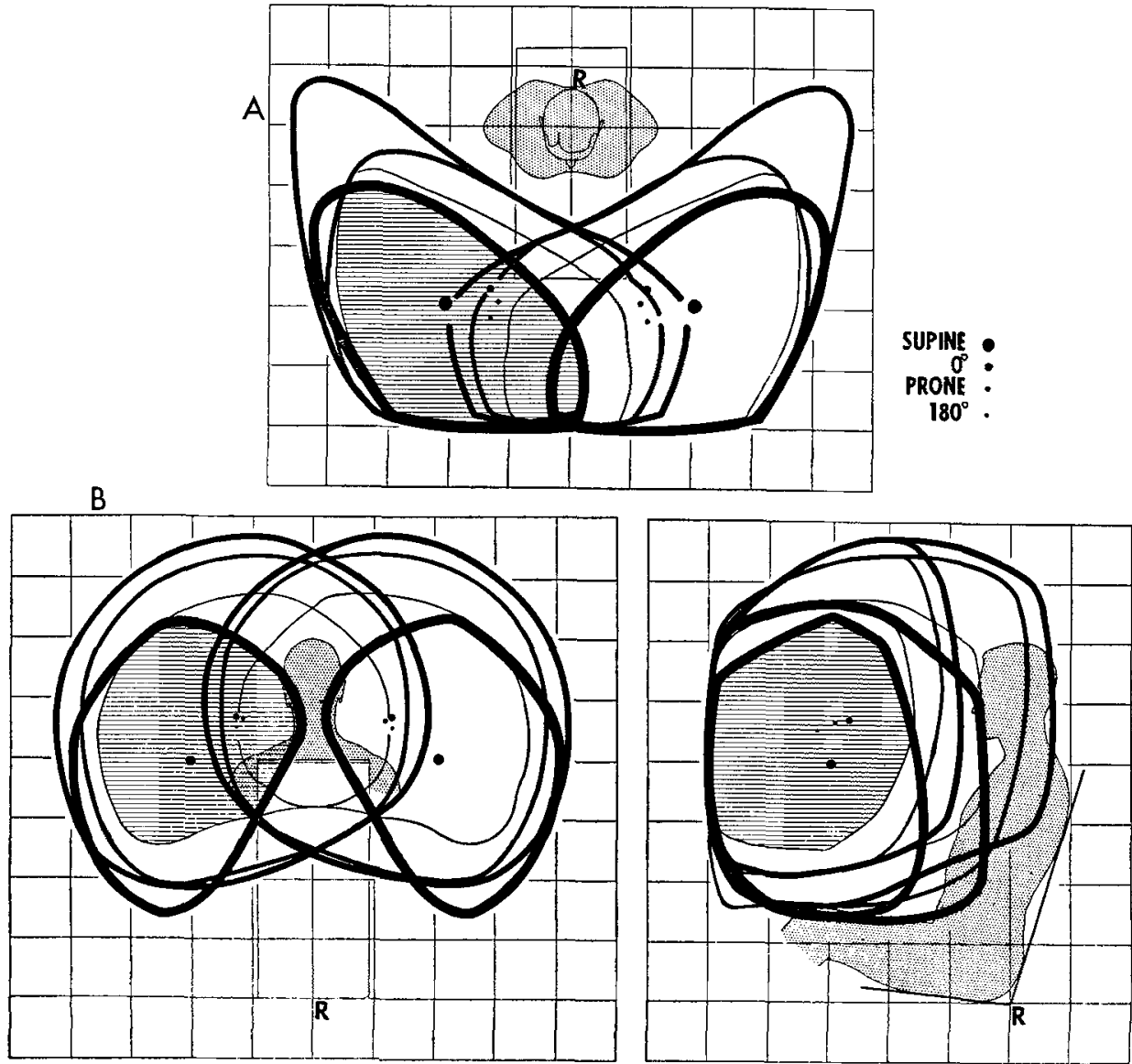

Fig. 10 The strophosphere resulting from superimposition of a transverse series of kinetospheres. Horizontal shading, the common region for hand motion; dots, the location of kinetosphere centroids. 




Fig. 11 Combined transverse and vertical strophospheres showing the common region for 8 hand orientations.

point). Relative to the average size subject, the cluster extended from nose tip or ear height to the lower end of the sternum; the centroids lay above the distal third of the thigh 2 1/2-6 in. posterior to the knee. The cluster of points extended obliquely from above the shoulder at the lower face level along a 45-degree angle downward and outward.

The segments of the limb have weight, and some muscular effort is required to support the limb in its various postures. This implies fatigue when the effort is prolonged. Muscular effort, however, is virtually eliminated when the hand hangs freely at the side of the body or when it is supported on the thighs or upon some surface such as chair arms or a work table or desk. The hand positions associated with these postures may be of primary practical importance as starting positions for hand motions.

\section{DISCUSSION}

Although figures 9 and 10 have been scaled off on a 6-in. grid (and fig. 11 was drawn to the same scale) it would be a mistake to assume that the dimensions given would provide more than a guide for the designing of a practical work space. The information derived from our study involves a specific sample of subjects and a set of experimental conditions which have been described above. Our aim in this paper has been twofold: (1) to develop an indirect approach to a functional anthropometry in the hope that further studies will produce still better answers, and (2) to present data which, if intelligently handled, should contribute to the designing of more effective work places, cockpits and driver compartments.

It would be entirely unnecessary to even think of gross work space dimensions if a cell or compartment the height of a 
worker and with a floor area $6 \mathrm{ft}$. (side to side) $\times 3.5 \mathrm{ft}$. (front to back), i.e., slightly larger than the grid of figure 12, could be provided. When, however, as in a vehicle, the available space must be reduced or when an efficient layout is important, an evaluation of the different regions within reach is warranted. Plans for a work space based upon our strophospheres may form part of a solution but to serve practical ends, it will be necesary to discuss several additional points:

1. The only kinetospheres (and strophospheres) that we have studied involve a forward aiming of the hand-the hand grid was initially set with the arm horizontal and pointing forward from the shoulder; all 8 hand grip orientations on which data were obtained were dependent on this one condition. If, instead, the left hand had been directed toward the right (i.e., bent elbow) a strophosphere space a little more than shoulder width and from the lap to the top of the head would be included (heavy dashed line bounding space " $A$ " in the three sketches of fig. 12); the fore-to-back extent would be about the same as the width. The region of rightleft overlap would include almost all of this new strophosphere space. Obliquelyforward hand orientations would intergrade from this region to that described above in our study. If the strophosphere were to involve a downward pointing of the hand, the grip-point space would extend from shoulder height or lower to just below seat level. If the hand were to be directed laterally, the associated kinetospheres would lie entirely to the side of the trunk and there would be no right-left overlap; the hand space would lie almost wholly within our strophosphere spaces; it would, however, bulge several inches more laterally (arm span, fig. 12, M). The upward-directed hand would likewise be largely within our kinetospheres (from chest height upward), but it would reach several inches higher. Precise predictions of space involved for the different hand postures cannot be made without accurate data and a detailed analysis. None of these additional strophospheres, however, would extend as far forward as those of our study.

2. An actual practical work area must in addition to room for hand movement provide space for the operator's body. The basic unit of the work area is the seat, and its " $R$ " point provides a suitable origin for the coordinate system to which dimensions are scaled. Since body stability is an essential for hand actions, seating area, seat height, floor area (Dempster, '55a), foot supports and the locations of foot controls all require careful planning. Despite several studies on seating (Lay and Fisher, '40; Randall et al., '46; Ákerblom, '48), no adequate statement of the mechanical principles involved in seat stability has as yet appeared. Seat backs, head rests, harnesses, arm rests, etc. are also involved with body stability. The planning for a specified man-machine operation should call for a total functional-mechanical analysis of work motions. Provisions for body stability, however, cannot be made secondary to those concerned with the placement of controls, equipment and paraphernalia. The work place must always have a convenient path for entrance and exit (shaded arrows "B," fig. 12).

3. The original data were derived from subjects for whom the heel-to-eye height was fixed at 39.5 in, as in the "fighter" cockpit. Thus the seat-to-floor distance was less for tall men than for shorter ones. The average seat height was nearly half that of a kitchen chair. The major difference between the high and the low seat, as far as the work place is concerned, is the relative spatial position of the feet relative to the manual space. If the floor area is adequate for the bracing action of the feet, body stability should be about as good in a chair of ordinary height as in the cockpit; then hand reach should be comparable in the two situations, and no discrepancies should be anticipated in the planning of a work area for seats of ordinary height. If the tilt of the seat back were notably more or less than the $17^{\circ}$ from vertical of our test seat, the fore-toback location of the shoulders relative to the " $R$ " point (and the several kinetospheres too) would be displaced slightly.

4. When our subjects sat upright in a balanced position with the trunk away from the seat back, the shoulders shifted forward an average of $2.5 \mathrm{in}$. relative to the " $R$ " point. Thus for a worker on a stool (without a back), each kinetosphere 

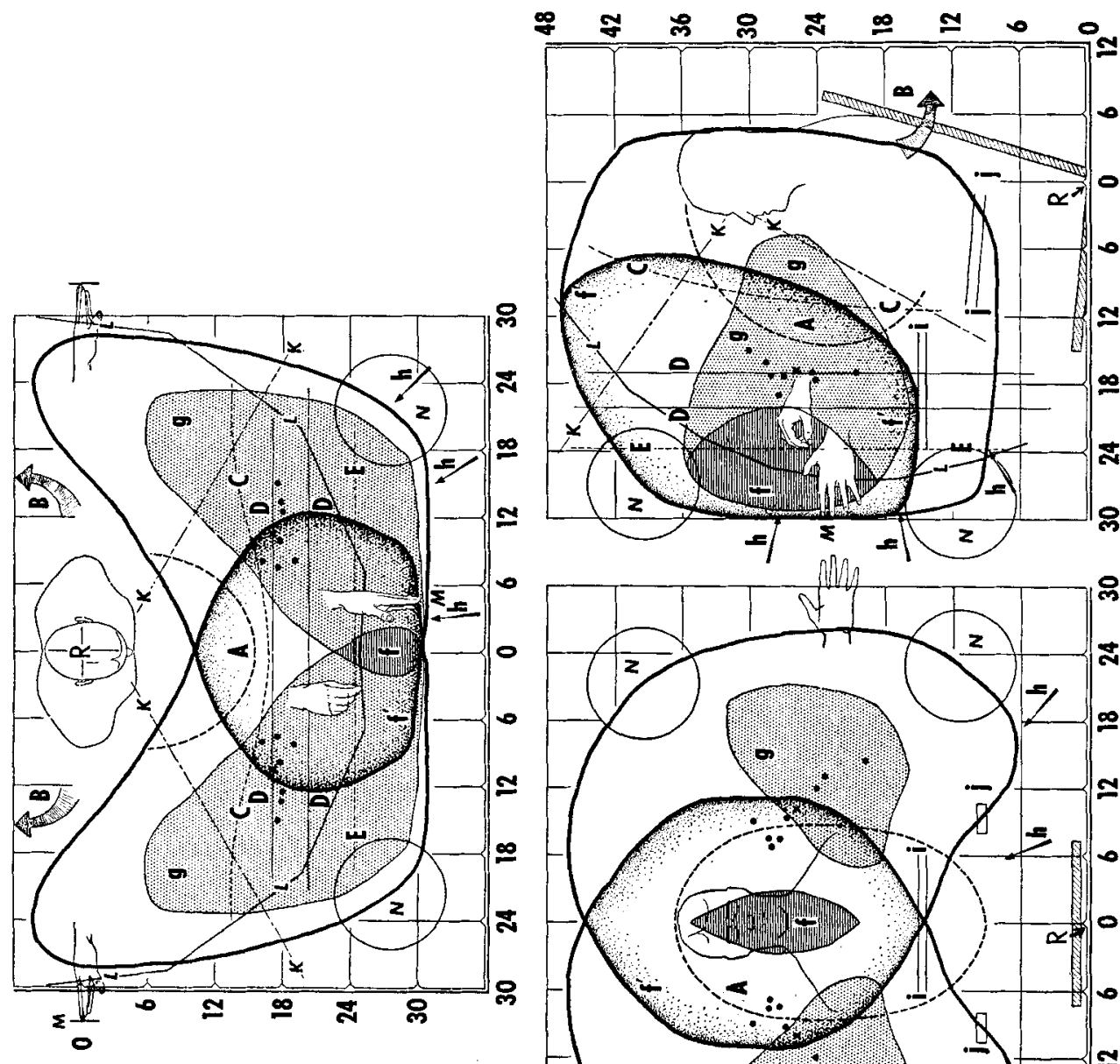

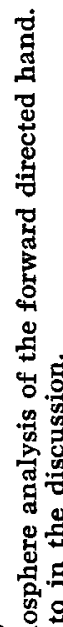

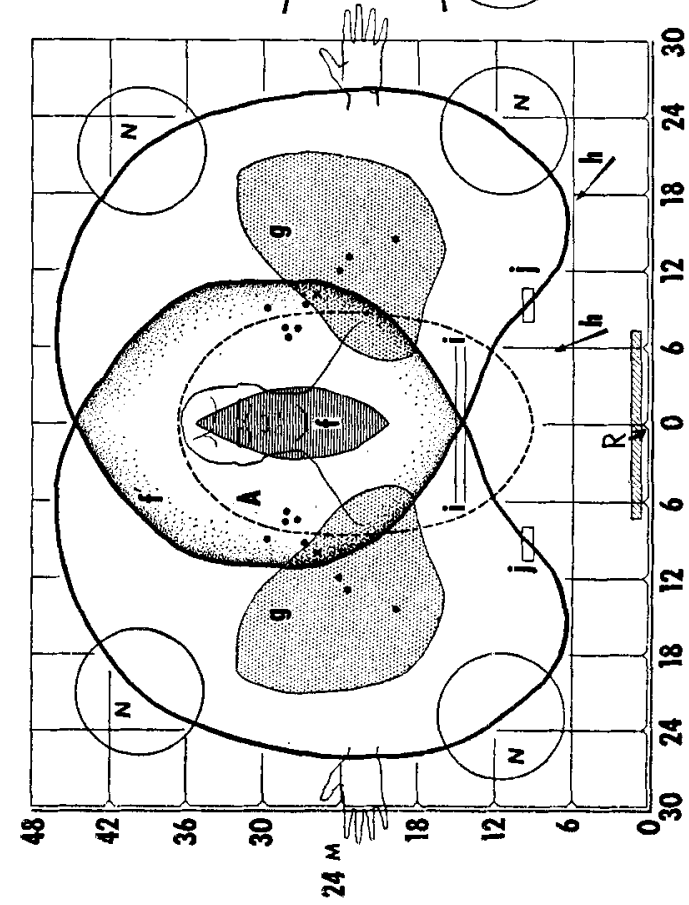

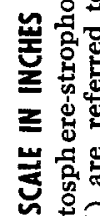
可 艺 量宛 흔 돈 년 导苍 承 엉 응. 믐 곤 总 43 올 㱐 
and the whole hand space is moved forward a predictable amount.

5. If an operator sits on a settee, as in the automobile, the backward movement of his elbows is limited by the seat back, and the potential hand space (roughly the region behind the dashed outline " $\mathrm{C}$," fig. 12) is unavailable.

6. Planning of the work area implies both a fixed chair position and a fixed placement of knobs, levers, cranks, implements, bins, etc. The chair distance and height may be adjustable to a degree for individuals of large or small size but these changes should be planned in advance. In "fighter" aircraft, for instance, an oblique up-and-back/down-and-forward adjustment has been employed to keep eye height constant and to provide a suitable pedal-to-seat distance.

7. If an operator were to sit before a transverse panel, he would be able to reach the largest possible area if the panel were set 17 to 20 in. ahead of the " $R$ " point (fig. 12, D-D). (The panel distance refers to " $R$ " point to grip point, and, in practical application, an additional distance " $\mathrm{X}$ " will relate to fingers or objects in the hand, etc.) For the $90^{\circ}$ grip position (i.e., antero-posterior grip axis), the mean panel distance would be 24 in. (fig. 12, E).

8. Our kinetospheres were defined as the outermost surface that the "grip point" would reach for the conditions tested. Push buttons or finger switches could be placed about 3 in. farther anterior, and they would still be within reach since the finger tip positions are about this distance in advance of the "grip point." The re-defined anterior surface of the work area should be understood as an outside range for placement of switches, knobs, etc. within convenient reach of the operator (without the necessity of his moving his trunk).

9. One may assume that critical or frequently used or emergency controls should be more accessible in the work area than items of occasional use. The region of right-left overlap of our kinetospheres (fig. 12, $f$, horizontal shading and $f^{1}$, marginal stipple) and the more proximal region " $A$ " in the figure would have certain advantages.

Similarly, the region common to different hand orientations (fig. 12, g, stipple) which is contiguous with " $\mathrm{f}$ " should be of maximum utility. The more proximal region " $A$ " in which different orientations are possible also should be important. In addition, the region near (and slightly below) the kinetosphere centroids (heavy dots, fig. 12) defines a position of high flexibility. The " $\mathrm{X}$ " within the cluster of dots represents the mean strophosphere centroid and the locus of this point in three dimensions relative to the $\mathrm{R}$-point should be noted. (The three projections of figure 12 are based on strophosphere sections which intersect at point "X.")

10. It is equally important that free movement of the limbs not be impeded by the faulty positioning of parts. McFarland's study of driver compartments in commercial automobiles ( $\mathrm{McF}$ arland et al., '53) emphasized that levers and controls have too commonly been placed so that they will neither accommodate the dimensions of men above average size nor permit free hand and foot movements. An illustration by Dempster ('55a, fig. 88) shows how foot movement is restricted when the knee cannot be raised beyond specified limits.

11. When the operator pulls a lever or hand grip toward his body, the most effective direction is toward his sternum (arrows, "h," fig. 12; Dempster, '58).

12. The table height and arm-rest positions (" $i$ " and " $j$ ") shown in figure 12, represent conventional heights above the " $R$ " point; measurements of elbow rest height by Hertzberg et al. ('54) are pertinent. Suitable arm rests (including table, steering wheel, etc.), if they do not impede necessary motions, should have value in reducing fatigue.

13. Several types of visual field (monocular field with fixed foveal focus, binocular field involving eye movement by ocular muscles, etc.) have long been recognized (Hering, '42). When the head is fixed but orbital muscles are free to move the eye, the visual field of each eye is framed above, below and on the nasal side by the eyebrow, cheek and nose. These parts of the facial anatomy combine to frame on all sides the composite field for precise binocular vision; in effect, this frame provides a hollow cone through which the subject looks. When the head is held in a fixed 
position, the sides of the cone diverge from the principle line of sight by about $60^{\circ}$ in all directions; a cone of $45^{\circ}$ radial divergence would probably include about $90 \%$ of people (Schneller, 1875; Hering, '42; Giroud, '57). If the head is oriented so that a horizontal plane cuts the right and left tragion and the left orbitale, it is said to be oriented relative to the Frankfort plane; when the head is so oriented, a horizontal plane cuts the cone so that $45^{\circ}$ of the purview lies above and $75^{\circ}$ below (Giroud, '57; a $30^{\circ} / 60^{\circ}$ ratio would include most people). Figure 12 ("k") shows that when a subject with an average sized binocular field for precise vision looks straight ahead with the head horizontal (i.e., on Frankfort plane), he does not see the whole work space without turning his head. He sees the region of rightleft overlap, the common region for different orientations of the hands and the centroid positions of the hands. The whole work space including the wings may be seen by turning the head (Danielson, '58). It should be apparent that if the essentials of a work operation are positioned within the K-K cone that only minimal head movements need be used. If the operation must be performed on a table the head and K-K cone will be tilted downward; focal distance, convergence, near-tofar-distance visual shifts and other factors may also call for attention.

14. Our strophospheres were derived from young men whose dimensions averaged a little higher than the mean of the average population. If a work area were to be planned for women of average stature ( $5 \mathrm{ft} .4 \mathrm{in}$.), the various dimensions from the " $R$ " point must be reduced by an appropriate ratio. A comparison of certain dimensions of male flying personnel and basic trainees with college and Air Force women (Wilder and Pfeiffer, '24; Daniels, Meyers and Churchill, '53; Daniels, Meyers and Worrall, '53; Hertzberg et al., '54) suggests that a reduction of our measurements by $6 \%$ would be a working approximation for the average female if joint flexibility is of the same order. Intermediate percentages or extrapolations beyond our measurements should be appropriate for special male worker groups.
15. The only previous measurements on work area dimensions are those of King et al. ('47). The dotted line " $L$ " in figure 12 shows the extent to which $97 \%$ of King's subjects could reach their finger tips. Forward arm-reach data (with shoulder protruded) for $97 \%$ of a test population (Hertzberg et al., '54) are shown also at " $\mathrm{m}$ " (outstretched white hand) in the figures. (The functional pinch-reach with shoulders back-also shown as a white hand-was shorter by 6 inches.)

16. When similar kinetospheres from different subjects are compared dimensionally, the boundary limits of the kinetospheres show intersubject variability due to differences in build, in kinematic behavior and in psychology. The circles of 5 in. radius (fig. 12, " $n$ ") suggest the order of magnitude of differences in the positions of boundary limits that would relate to about $90 \%$ of the subjects.

Several authors (McFarland et al., '55, '58; Hertzberg, '56) have argued that when members of a population are to be fitted, the dimensions of the 10th to 90 th or 5 th to 95 th percentiles should be used instead of the average. The use of the 90th or 95th percentile dimension will be obvious when the minimal clearance space for larger people is involved; the difference in range between a high and a low percentile value should be important too in predetermining dimensions for adjustments such as seat position or seat height; but it is questionable whether this principle need apply rigidly to a work area concerned with hand motions. Here we are dealing with flexible rather than with fixed characteristics. The work area problem is one that relates to the efficient placement of controls and equipment rather than to the mere enclosure of a person who is a member of a population; the extreme limits of the usable space are of little importance for frequent motions, they are of more concern for storage and for the placement of rarely used controls. The subject should, however, be able to reach conveniently the boundary limits of the ergosphere. If unrestrained by tight shoulder harness, slight body movements should permit any normal adult to reach the limits of our work area -forward and to the side (but not, for 
the smallest people, upward). By bending his trunk, an operator should be able to reach about 15 in. forward and 9 in. to the side without becoming unbalanced. A detailed job analysis should determine whether average or enlarged work space dimensions are needed.

17. The initial one fifth-scale tracings of our photo records involved a clockwise and a counterclockwise hand circuit of a glow-lamp over the grip point. The two curves at places often coincided while at others either the clockwise or counterclockwise was outermost. The mean distance between the two circuits measured at 8 points on their circumference (at $45^{\circ}$ intervals) for a plane above the knees and another over the thighs, 12 inches more posterior, was 1.4 in. The difference between the mean curve we drew in to provide data for our original kinetospheres and the actual light traces was thus \pm 0.7 in. The subjects often overshot the kinetosphere boundary by this amount. Twice the S.D. was \pm 2.14 in.; thus about twofifths of the \pm 5 in. variability factor mentioned above (paragraph 16; fig. 12, "N") should easily be within the reach of any subject without extraneous trunk movements.

Dimensional differences in limb segments, differences in joint range and differences in control due to handedness should be expected between the right and left sides of a subject. When we arbitrarily studied motions of only the left hand, our measures of variability could not be exhaustive.

18. In two instances, prone and $0^{\circ} \mathrm{ki}$ netosphere records for the forward projecting hand were taken on standing subjects. The general shape and location of the kinetosphere relative to the trunk were roughly comparable to those for the same subjects seated; the principal difference was that the knees and thighs did not interfere and that the kinetospheres had a smooth convex contour below reaching to the level of the pubic symphysis. The forward and left lateral ranges were reduced slightly since the trunk swayed in the opposite direction when the upper limb was stretched out in the more or less horizontal positions.
McFarland et al. ('58) remind us that a workman does not live in a vacuum nor in an ivory tower; he operates in an environment of ponderable things. We should not ignore even the weight and inertia of his own body parts. Man-machine systems are complex and the requisite background for effectively designing work areas and the placement of controls will involve: (1) more and better data on body kinematics and dynamic anthropometry (like those we have explored in this paper), (2) further information on body size and clearance tolerances (including measurements on women), (3) improved measurements on strength in relation to posture and stability and, (4) increased knowledge about the energy expenditure (i.e., rate of oxygen utilization) involved in different tasks. Furthermore, the actual confirmation of drawing-board plans must involve real people as subjects. Such intangibles as comfort and fatigue and such specific job features as the purpose and character of the work, production schedules, motivation, noise and safety hazards will continue to provide appreciable areas for compromise and practical judgments.

\section{SUMMARY}

The anthropometry of the manual work area was approached by an indirect method using photo records of time exposures showing the motions of a tiny neon lamp at the hand grip. The records of 22 male subjects were analyzed for 8 sets of motions involving the forward-directed hand and different grip orientations. Techniques were developed for defining the limits of the space within reach relative to the mid-sagittal junction of the seat and chair back. Graphical records of the different hand-range spaces were grouped and compared to bring out variability data, the extent of right-left hand overlap, regions of maximum hand flexibility, mean hand positions, etc. The data have been discussed in relation to the geometry of the more effective hand positions and in relation to practical problems of work space designing.

\section{LITERATURE CITED}

Akerblom, B. 1948 Standing and Sitting Posture. A. B. Nordiska Bokhandeln, Stockholm, 187 pp. 
Albert, E. 1876 Zur Mechanik des Huftgelenkes. Med. Jahrb. (Wein), pp. 105-131.

Barnes, R. M. 1949 Motion and Time Study. 3rd edition. John Wiley and Sons, New York, 559 pp.

Barter, J. T., I. Emanuel and B. Truett 1957 A statistical Evaluation of joint range data. WADC Tech. Note 57-311. Wright Air Development Center, Wright-Patterson Air Force Base, Ohio. (ASTIA Document No. 131028), $22 \mathrm{pp}$.

Branson, B. 1952 Time and Motion on the Farm. Faler and Faber, London, 123 pp.

Braus, H. 1954 Anatomie des Menschen. 3rd. edition. Bd. 1, Bewegungsapparat. J. Springer, Berlin, 789 pp.

Chapanis, A., W. R. Garner and C. T. Morgan 1949 Applied Experimental Psychology, Human Factor in Engineering Design. John Wiley and Sons, New York, 434 pp.

Daniels, G. S., H. C. Meyers, Jr. and S. H. Worrall 1953 Anthropometry of WAF basic trainees. WADC Tech. Rep. 53-12, Wright Air Development Center, Wright-Patterson Air Force Base, Ohio, 103 pp.

Daniels, G. S., H. C. Meyers and E. Churchill 1953 Anthropometry of male basic trainees. WADC Tech. Rep. 53-49, Wright Air Development Center, Wright-Patterson Air Force Base, Ohio, 99 pp.

Danielson, R. W. 1958 Relationship of fields of vision to safety in driving. Traffic Safety Res. Rev., 2: 8-25.

Darcus, H. D. 1951 The maximum torques developed in pronation and supination of the right hand. J. Anat., 85: 55-67.

Darcus, H. D., and N. Salter 1953 The amplitude of pronation and supination with the elbow flexed to a right angle. Ibid., 87: 169-184.

Davis, L. E. 1949 Human factors in design of manual machine controls. Mech. Engin., 71: 811-816.

Dempster, W. T. 1955a Space requirements of the seated operator: geometrical, kinematic, and mechanical aspects of the body with special reference to the limbs. WADC Tech. Rep. 55-159. Wright Air Development Center, Wright-Patterson Air Force Base, Ohio, 254 pp. $1955 \mathrm{~b}$ The anthropometry of body action. Ann. N. Y. Acad. Sci., 63: 559-585.

1956 The range of motion of cadaver joints. Univ, Mich. Med. Bull., 22: 364-379.

1958 An analysis of two-handed pulls using free body diagrams. J. Appl. Physiol., 13: $469-480$.

Fick, R. 1904-1910-1911 Handbuch der Anatomie und Mechanik der Gelenke. In: K. v. Bardeleben: Handbuch der Anatomie des Menschen. G. Fischer, Jena., 2(1): 512 pp., 2(2): 376 pp., 2(3): 688 pp.

Fischer, O. 1907 Kinematik organischer Gelenke. F. Vieweg und Sohn, Braunschweig, 261 pp.

Gaughran, G. R. L., and W. T. Dempster 1955 Force analyses of horizontal two-handed pushes and pulls in the sagittal plane. Human Biol., 28: $67-92$.
Gilliland, A. R. 1921 Norms for amplitude of voluntary movements, J. Am. Med. Assoc., 77: 1357.

Giroud, E. 1957 Zur Bestimmung des Blickfeldes. V. Graeff's Arch, für Ophth., 159: 66-80.

Glanville, A. D., and G. Kreezer 1937 The maximum amplitude and velocity of joint movements in normal male human adults. Human Biol., 9: 197-211.

Hering, E. 1942 Spatial Sense (Engl. transl. by C. A. Raddle) Am. Acad. Optom., Baltimore, pp. 83-91.

Hertzberg, H. T. E. 1956 Some contributions of applied physical anthropology to human engineering. Ann. N. Y. Acad. Sci., 63: 616-629.

Hertzberg, H. T. E., G. S. Daniels and E. Churchill 1954 Anthropometry of flying personnel1950. WADC Tech. Rep. 52-321. Wright Air Development Center, Wright-Patterson Air Force Base, Ohio, 134 pp.

Hick, W. E., and J. A. V. Bates 1950 The human operator of control mechanisms. Gt. Brit. Ministry of Supply, Monogr., 17-204, 64 pp.

Hugh-Jones, P. 1945 Some physiological as pects of tank driving controls, part 3 . The maximum force exertable on hand controls and how this varies with different positions of the control relative to the seat. Gt. Brit., Med. Res. Council. Subcomm. on AFV. BPC 410 , PL 158

King, B. G. 1948 Measurements of man for making machinery. Am. J. Phys. Anthrop., 6 . 341-351.

- 1952 Functional cockpit design. Aeronautical Eng. Rev., 11: 32-40.

King, B. G., D. J. Morrow and E. P. Vollmer 1947 Cockpit studies - The boundaries of the maximum area for the operation of manual controls. Naval Medical Institute, Bethesda, Maryland, Proj. X-651, Rep. 3, 13 pp.

Lanz, T. V., and W. Wachsmuth 1935-1938 Praktische Anatomie, Ein Lehr- und Hilfsbuch der anatomischen Grundlagen ärtzliches Handelns. J. Springer, Berlin, 1(3): 276 pp.; 1(4) Bein und Statik, $485 \mathrm{pp}$.

Lay, W. E., and L. C. Fisher 1940 Riding com fort and cushions. S.A.E. Л., 47: 482-496.

MacNeil, R. A. 1954 Designing for operator size and shape. Electrical Manufacturing, 53. 241-242.

McFarland, R. A. 1953 Human engineering. Aviat. Age, 19: 214-219.

McFarland, R. A., A. Damon and H. W. Stoudt 1955 The application of human body size data to vehicular design. Soc. Auto. Eng. Spec. Publ. Dept. (SP-142), New York, 16 pp.

1958 Anthropometry in the design of the driver's workspace. Am. J. Phys. Anthrop. 16: 1-23.

McFarland, R. A., A. Damon, H. W. Stoudt, A. L. Moseley, J. W. Dunlap and W. A. Hall 1953 Human Body Size and Capabilities in the Design and Operation of Vehicular Equipment. Harvard School of Public Health, Boston, 239 pp.

Mollier, S. 1938 Plastische Anatomie: Die Konstruktive Form des Menschlichen Körpers. and edition. Bergman, Munich, $280 \mathrm{pp}$. 
Randall, F. E., A. Damon, R. S. Benton and D. I. Patt 1946 Human body size in military aircraft and personal equipment. Rep. 5501. U. S. Army Air Forces, Air Material Command. Wright Field, Ohio, 333 pp.

Salter, N., and H. D. Darcus 1952 The effect of the degree of elbow flexion on the maximum torques developed in pronation and supination of the right hand. J. Anat., 86: 197-202.

Schneller, Dr. 1875 Studien über das Blickfeld. v. Graefe's Arch. für Ophthal., 21: 133198.

Sinelnikoff, E., and M. Grigorowitsch 1931 Die Beweglichkeit der Gelenke als sekundäres geschlechtliches und Konstitutionelles Merkmal. Zts. f. Konstitutionslehre, 15: 679-693.

Strasser, H. 1908-1917 Lehrbuch der Muskelund Gelenkmechanik. J. Springer, Berlin. 1.
(1908) 212 pp.; 2. (1913) 474 pp.; 3. (1913) 420 pp.; 4. (1917) 376 pp.

Taylor, C. L., and A. C. Blaschke 1951 A method for kinematic analysis of motions of the shoulder, arm, and hand complex. Ann. N. Y. Acad. Sci., 51: 1251-1265.

Wallichs, E., and F, Hulverscheidt 1935 Die Bedienbarkeit von Handgriffen an Vorrichtungen. Werkstattstechnik und Werksleiter, 29: 193-197.

Whitney, R. J. 1958 The strength of the lifting action in man. Ergonomics, 1: 101-128.

Wilder, H. H., and M. W. Pfeiffer 1924 The bodily proportions of women in the United States; based upon measurements taken from one hundred Smith College students. Proc. Amer. Acad. Arts and Sciences, 59: 441-603. 